\title{
GESTACIÓN POR SUSTITUCIÓN: ORDEN PÚBLICO INTERNACIONAL VS. ORDEN PÚBLICO EUROPEO
}

\section{SURROGACY: INTERNATIONAL PUBLIC POLICY VS. EUROPEAN PUBLIC POLICY}

\author{
María José Castellanos Ruiz \\ Profesora Ayudante Doctora de Derecho Internacional Privado \\ Universidad Carlos III de Madrid \\ ORCID ID: 0000-0003-1869-4488
}

Recibido: 07.07.2021 / Aceptado: 19.07.2021

DOI: https://doi.org/10.20318/cdt.2021.6310

\begin{abstract}
Resumen: En el presente trabajo se estudiará cuándo se activa el orden público internacional, en relación con los contratos de gestación por sustitución, tanto en España, como en los países de nuestro entorno, concretamente en Francia y en Italia.

Son Estados en los que, por un lado, existe una regulación que no permite la gestación por sustitución, como sucede en España, por lo que, en caso de que se lleven a cabo este tipo de prácticas en un Estado extranjero donde son válidas, es susceptible de que se active la excepción de orden público internacional de dichos Estados; pero que, por otro lado, a diferencia de lo que ocurre en España, el orden público europeo está jugando un papel importante, para que sea posible el reconocimiento de la filiación de los menores a favor de los padres comitentes.

Palabras clave: gestación por sustitución, maternidad subrogada, conflicto de Leyes, reconocimiento de decisiones, certificaciones registrales extranjeras, Lex Fori, filiación, Derecho internacional privado, Forum Shopping, fraude de Ley, orden público internacional, orden público europeo, interés superior del menor.
\end{abstract}

Abstract: In this paper we will study when international public policy is activated, in relation to surrogacy, both in Spain and in neighboring countries, specifically in France and Italy.

These are States in which, on the one hand, there is a regulation that does not allow surrogacy, as is the case in Spain, therefore, in the event that this type of practice is carried out in a foreign State where they are valid, it is capable of activating the international public order exception of mentioned States; but that, on the other hand, unlike what happens in Spain, european public policy is playing an important role, so that the recognition of the parentage of minors in favor of the intended parents is possible.

Keywords: surrogacy, surrogate mothers, surrogate motherhood, conflict-of-laws, recognition and enforcement of foreign decisions, foreign birth certificates, lex fori, filiation, Private international law, Forum Shopping, evasion of the law, international public policy, european public policy, interests of the child.

Sumario: I. Introducción. II. Orden público internacional en España en relación con la gestación por sustitución. 1. Sentencia del Tribunal Supremo de 6 de febrero de 2014. A) El orden público internacional español. B) El principio de “interés superior del menor". 2. Auto del Tribunal Supremo de 2 de febrero de 2015. 3. Sentencia de la Audiencia Provincial de Islas Baleares de 27 de abril de 2021. III. Orden público internacional en Francia en lo referente a la gestación por sustitución. 1. Sentencias del TEDH de 26 de junio de 2014, asuntos Mennesson y Labassee. A) El derecho al respeto a la "vida privada y familiar". B) Concepción restrictiva y específica de "orden público inter- 
nacional". 2. Dictamen del TEDH de 10 de abril de 2.019. IV. Orden público internacional en Italia en materia de gestación por sustitución. 1. El orden público interncional italiano. A) El principio de “interés superior del menor”. B) El grado de apreciación de los Estados. 2. Orden público internacional vs. principios internacionales del CEDH. V. Conclusiones.

\section{Introducción}

1. Desde hace varios años se aborda el tema del orden público europeo, como consecuencia de la jurisprudencia tanto del Tribunal de Justicia de la Unión Europea (TJUE) como del Tribunal Europeo de Derechos Humanos (TEDH) ${ }^{1}$. Lo cual, ha provocado que nos planteemos la cuestión de la existencia de un orden público europeo, y lo que es más importante, qué características lo conforman, de manera que pueda afirmarse, con rotundidad, que estamos en presencia de un orden público europeo con contornos propios, diferente del orden público internacional de cada Estado.

Pues que el orden público europeo es diferente del orden público internacional de cada Estado miembro, efectivamente es algo aceptado por la mayor parte de la doctrina ${ }^{2}$. Pero entonces surge la disyuntiva de en qué supuestos el orden público europeo va a prevalecer sobre el orden público internacional del Estado miembro en cuestión, al menos en relación con la jurisprudencia más reciente.

2. Así, por ejemplo, la decisión del Tribunal de Justicia de la Unión Europea del 2018, en el asunto Coman y otros, ha reforzado la libre circulación de los matrimonios del mismo sexo contraídos en el territorio de la Unión, aseverando que también posee la cualidad de "cónyuge" la pareja del ciudadano de la Unión, de su mismo sexo, que haya contraído matrimonio en cualquiera de los Estados miembros conforme a su legislación civil $^{3}$. En este sentido, se ha establecido el alcance del concepto de "cónyuge", de forma que no se restrinja la libre circulación de los matrimonios del mismo sexo, a pesar de que, en Rumanía, la celebración de este tipo de matrimonios no está permitido y atenta contra el orden público internacional de dicho Estado cualquier efecto que pudiese desplegar.

Así pues, el TJUE considera que el reconocimiento de los matrimonios del mismo sexo, únicamente con el objeto de conceder un derecho de residencia -que es lo que se demandaba en el litigio principal- no atenta contra la identidad nacional ni amenaza el orden público del Estado miembro afecta$\mathrm{do}^{4}$. No se trata de que Rumanía contemple la institución del matrimonio entre personas del mismo sexo, sino que se limite a reconocer tales matrimonios, contraídos de forma válida en otro Estado miembro

\footnotetext{
${ }^{1}$ S. Poillot-Peruzzetto, "La incidencia de las modalidades del reconocimiento de decisiones en el Espacio Judicial Europeo en la dualidad Orden Público Nacional/Orden Público Europeo”, AEDIPr, vol. 9, 2009, pp. 169-199, esp. p. 187; J. Kramberger Skerl, "European Public Policy (With an Emphasis on Exequatur Proceedings)", Journal of Private International Law, 2011, pp. 461-490, esp. pp. 462-463; S. ÁlvAREZ GonZÁlez, ¿Orden público europeo versus orden público internacional de cada Estado?, en N. Bouza i Vidal/ C. García i Segura/ A.-J. Rodrigo Hernández, P. Pareja Alcaraz (coords.), La gobernanza del interés público global: XXV Jornadas de la Asociación Española de Profesores de Derecho Internacional y Relaciones Internacionales, Tecnos, Madrid, 2015, pp. 146-, 181, esp. pp. 146-149.

${ }^{2}$ A.-V.-M. StRUYCKen, "Les consequences de l'integration européenne sur le 'développement du droit international privé", Collected Courses of the Hague Academy of International Law, vol. 232, 1992, pp. 274 ss.; M. FALlon, "Les conflits de lois et de juridictions dans un espace économique intégré. L'experience de la Cornmunauté Européenne", Collected Courses of the Hague Academy of International Law, vol. 253, 1995, pp. 255-257; I. GARCíA RodríGUEz, "Derecho aplicable y orden público comunitario”, Revista de Instituciones Europeas, 1993, pp. 901-942.; S. Álvarez GonZÁLEZ, ¿Orden público europeo versus orden público internacional de cada Estado?, en N. Bouza i Vidal/ C. García i Segura/ A.-J. Rodrigo Hernández, P. Pareja AlCARAZ (coords.), La gobernanza del interés público global: XXV Jornadas de la Asociación Española de Profesores de Derecho Internacional y Relaciones Internacionales, Tecnos, Madrid, 2015, p. 148.

${ }^{3}$ STJUE 5 julio 2018, Relu Adrian Coman y otros c. Inspectoratul General pentru Imigrări y Ministerul Afacerilor Interne, C-673/16 (ECLI:EU:C:2018:385).

${ }^{4}$ STJUE 5 julio 2018, Relu Adrian Coman y otros c. Inspectoratul General pentru Imigrări y Ministerul Afacerilor Interne, C-673/16 (ECLI:EU:C:2018:385), apartado 46.
} 
de conformidad con el Derecho de este, y ello a los solos efectos del ejercicio de los derechos que se derivan del Derecho de la Unión 5 .

3. En este mismo sentido, y en relación con la gestación por sustitución -que es el tema que nos ocupa en el presente trabajo-, en otras dos sentencias del 2014, asuntos Mennesson y Labassee, el Tribunal Europeo de Derechos Humanos situó la protección del principio del "interés superior del menor" por encima de cualquier otro principio, incluso por encima del orden público internacional del país en cuestión, en este caso del Estado francés ${ }^{6}$.

En ambos asuntos, el Tribunal Europeo de Derechos Humanos es partidario de una concepción restrictiva y específica del orden público internacional: a) restrictiva en el sentido de que sólo se podrá denegar la inscripción de la filiación de los menores nacidos bajo un contrato de gestación por sustitución a favor de los padres comitentes si se prueba que el menor ha sido objeto de comercio, que la madre gestante fue engañada y prestó un consentimiento no informado, o que prestó sus servicios con ánimo de lucro o que la mujer gestante fue obligada a prestar sus servicios por una situación de pobreza, entre otros; y b) específica, porque las circunstancias anteriores sólo pueden valorarse en el caso concreto, pues en toda intervención de orden público los datos del caso son relevantes?

4. En definitiva, cada Estado ha establecido su propio orden público internacional, definido este como el conjunto de principios fundamentales que garantizan la cohesión jurídica de la sociedad de ese país. Sin embargo, dicho orden público internacional de un Estado puede estar en contradicción con los principios que protege el Derecho de la Unión Europea, como es el Derecho a la "libre circulación de personas", el Derecho a un "nombre y apellidos únicos" o el Derecho al "respeto a la vida privada y familiar"; de forma que una situación jurídica que ha sido creada y es válida en un Estado miembro, cuando cruza la frontera de dicho Estado, no es reconocida en otros Estados miembros.

Si bien, es importante señalar el contenido del orden público europeo, también adquiere especial relevancia cuáles han de ser los límites del orden público internacional de los Estados miembros, a raíz de la jurisprudencia más reciente tanto del TJUE como del TEDH.

5. Aunque en el presente trabajo se abordará el orden público europeo en relación con la gestación por sustitución, tras dicho análisis, podremos dar una respuesta aproximada a las cuestiones planteadas. Es precisamente en relación con los contratos de gestación por sustitución, en donde ha podido observarse en los últimos años, la existencia de un orden público europeo, en principio diferente del orden público internacional de los Estados miembros.

Para ello, se estudiará cuándo se activa el orden público internacional, en relación con los contratos de gestación por sustitución, tanto en España, como en los países de nuestro entorno, concretamente en Francia y en Italia. Son Estados en los que, por un lado, existe una regulación que no permite la gestación por sustitución, como sucede en España, por lo que, en caso de que se lleven a cabo este tipo de prácticas en un Estado extranjero donde son válidas, es susceptible de que se active la cláusula de orden público internacional de dichos Estados; pero que, por otro lado, a diferencia de lo que ocurre en España, el orden público europeo está jugando un papel importante, para que sea posible el reconocimiento de la filiación de los menores a favor de los padres comitentes. En el caso de Italia concretamente, en abril del 2020, se planteó ante el Tribunal Constitucional italiano la cuestión de si la

${ }^{5}$ STJUE 5 julio 2018, Relu Adrian Coman y otros c. Inspectoratul General pentru Imigrări y Ministerul Afacerilor Interne, C-673/16 (ECLI:EU:C:2018:385), apartado 45.

${ }^{6}$ STEDH 26 junio 2014, Mennesson c. Francia, 65192/11 (JUR\2014\176908), apartados 63 y 82; STEDH 26 junio 2014, Labassee c. Francia, 65941/11 (JUR\2014\176905), apartados 60-61.

${ }^{7}$ A. Hernández Rodríguez, "La determinación de la filiación de los nacidos en el extranjero mediante gestación por sustitución: ¿Hacia una nueva regulación en España?”, Cuadernos de Derecho Transnacional (CDT), vol. 6, nº 2, octubre 2014, pp. 169-173; A.-L. Calvo Caravaca/ J. Carrascosa GonzÁlez, "La gestación por sustitución y Derecho internacional privado. Más allá del Tribunal Supremo y del Tribunal Europeo de Derechos Humanos", Cuadernos de Derecho Transnacional (CDT), vol. 7, n² 2, octubre 2015, pp. 94-95; J. Carrascosa GonzÁlez, "Filiación natural", en A.-L. Calvo Caravaca/ J. Carrascosa GonZÁlez (dirs.), Tratado de Derecho Internacional Privado, Tomo II, Tirant lo Blanch, Valencia, 2020, pp. 1895-1896. 
interpretación que se ha venido haciendo por parte de los tribunales italianos -de no reconocimiento de la filiación a favor de los padres comitentes porque atenta contra el orden público italiano- es coherente con la Constitución italiana ${ }^{8}$.

\section{Orden público internacional en España en relación a la gestación por sustitución}

6. Para entender cuándo se activa la cláusula de orden público internacionl español en materia de gestación por sustitución, se explicará el conocido caso de los "niños de California". En relación con el mismo, el Tribunal Supremo, por medio de Auto de fecha 2 de febrero de 2015, resolviendo el incidente de nulidad de actuaciones que se planteó frente a la Sentencia del TS de 6 de febrero de 2014, dictaminó -en el mismo sentido en que lo hizo en la sentencia del 2014-, que no se había producido una vulneración del derecho a la identidad, ni del derecho al respeto de la vida privada de los menores nacidos por maternidad subrogada, como consecuencia de la no inscripción de la filiación de los menores en el Registro Civil9.

En este asunto, como la legislación española prohíbe los contratos de gestación por sustitución, el Tribunal Supremo situó al orden público internacional español por encima del principio del "interés superior del menor", recogido en el art. 3 de la Convención sobre los Derechos del Niño y que fue alegado por los padres comitentes ${ }^{10}$.

7. Sin embargo, una Sentencia de la Audiencia Provincial de las Islas Baleares de 27 de abril de 2021, en el que el asunto era la determinación de la filiación de una menor nacida en Rusia mediante un contrato de gestación por sustitución, ha venido a situar el principio del interés superior del menor por encima del orden público internacional español; si bien se deben tener en cuenta las circunstancias concretas del asunto en cuestión ${ }^{11}$.

\section{Sentencia del Tribunal Supremo de 6 de febrero de 2014}

8. Dicha sentencia resuelve el famoso y mediático caso de los "niños de California", nacidos mediante un contrato de gestación por sustitución, descrito de este modo porque como consecuencia de la jurisprudencia generada, la doctrina se halla dividida en relación al mismo ${ }^{12}$.

${ }^{8}$ L. Acconciamessa, "The Italian Constitutional Court Asked to Rule on Surrogacy Arrangements and Public Police”, EAPIL (The European Association of Private International Law), 28 septiembre 2020, disponible en https://eapil.org/2020/09/28/ the-italian-constitutional-court-asked-to-rule-on-surrogacy-arrangements-and-public-policy/?utm_source=mailpoet\&utm medium=email\&utm_campaign=new-contents-on-the-eapil-blog_2 (consultado el 1 de abril de 2021).

${ }^{9}$ Auto TS (Sala de lo Civil) de 2 febrero de 2015 (RJ $2015 \backslash 141$ ). En el auto, el TS también estableció la improcedencia de la vulneración de los tres derechos fundamentales alegada por los recurrentes, al señalar la ausencia de vulneración del derecho a la tutela judicial efectiva, del derecho a la igualdad sin sufrir discriminación y del derecho a la intimidad familiar.

${ }^{10}$ Vid. art. 3 de la Convención sobre los derechos del niño hecha en Nueva York el 20 de noviembre de 1989 (BOE núm. 313, 31 diciembre 1990), en vigor para España desde el 5 de enero de 1991.

${ }^{11}$ SAP Islas Baleares núm. 207/2021 de 27 abril (JUR\2021\163294).

${ }^{12}$ Vid. R. Bercovitz Rodríguez-Cano, "Hijos made in California", Aranzadi Civil Revista Doctrinal, no 3 (Tribuna), Aranzadi-Westlaw, Pamplona, 2009, pp. 1-2; A. QuiÑones Escámez, "Doble filiación paterna de gemelos nacidos en el extranjero mediante maternidad subrogada. En torno a la RDGRN de 18 de febrero de 2009”, Indret, $\mathrm{n}^{\circ} 3$, Editorial Universitat Pompeu Fabra, Barcelona, julio 2009, pp. 1-42; A.-L. Calvo Caravaca/ J. Carrascosa González, “Gestación por sustitución y Derecho internacional privado: Consideraciones en torno a la Resolución de la Dirección General de los Registros y del Notariado de 18 de febrero de 2009", Cuadernos de Derecho Transnacional (CDT), vol. 1, no 2, octubre 2009, pp. 294-319; ID., "Notas críticas en torno a la Instrucción de la Dirección General de los Registros y del Notariado de 5 octubre 2010 sobre régimen registral de la filiación de los nacidos mediante gestación por sustitución", Cuadernos de Derecho Transnacional (CDT), vol. 3, $\mathrm{n}^{\circ}$ 1, marzo 2011, pp. 247-262; E. LAMm, Gestación por sustitución. Ni maternidad subrogada, ni vientres de alquiler, Publicacions i Edicions de la Universitat de Barcelona, Barcelona, 2013, pp. 1-102; E. Corral García, "Los menores nacidos mediante gestación por sustitución no pueden ser inscritos en el Registro Civil. Comentario a la STS de 6 de febrero de 2014", Revista Crítica de Derecho Inmobiliario, no 744, 2014, pp. 1910-1923; S. VILAR GonzÁLEz, "Situación actual de la gestación por sustitución", Revista de Derecho UNED, n 14, 2014, pp. 897-934; L. Álvarez DE TolEDo, "El futuro de 
Este caso es el de una pareja formada por dos varones de nacionalidad española y con residencia habitual en España, que se casaron en el año 2005. Éstos se trasladan a San Diego (California), y allí realizan un contrato de gestación por sustitución, en virtud del cual la madre gestante dio a luz a gemelos, dos niños, el 24 de octubre de 2008, a cambio de lo cual recibió una contraprestación económica ${ }^{13}$. La mujer fue inseminada artificialmente con el material genético de los dos hombres, de manera que se dan las circunstancias de que, además de los padres comitentes son los padres biológicos de los dos menores ${ }^{14}$.

Una vez nacidos los menores, se dicta la resolución judicial que determina la filiación a favor de los padres comitentes, lo que les permite obtener la certificación registral extranjera en la que se constata: por una parte, la inscripción de los menores y, por otra, la filiación determinada a favor de dicho matrimonio ${ }^{15}$. Es importante señalar que en dicha certificación registral se constatan ambos términos, al igual que en la Resolución de la DGRN (Dirección General de los Registros y del Notariado) de 18 de febrero de 2009, dictada como resultado de la solicitud de inscripción en España de los aspectos recogidos en dicha certificación extranjera ${ }^{16}$.

En dicha Resolución del 2009, la DGRN, actualmente renombrada como Dirección General de Seguridad Jurídica y Fe Pública, estima que la autoridad extranjera ha constatado la realidad de unos hechos que, en lo referido a la gestación por sustitución, incluye el nacimiento del bebé, la entrega del mismo, la renuncia de la parte gestante y la determinación de la filiación a favor de la parte comitente ${ }^{17}$. Sin embargo, existen autores que consideran que la DGRN parece olvidarse de que tal realidad jurídica

la maternidad subrogada en España: entre el fraude de Ley y el correctivo de orden público internacional", Cuadernos de Derecho Transnacional (CDT), vol. 6, nº 2, octubre 2014, pp. 5-49; A. HeRnÁNDEZ RodRíGUEZ, "La determinación de la filiación de los nacidos en el extranjero mediante gestación por sustitución: ¿Hacia una nueva regulación en España?”, Cuadernos de Derecho Transnacional (CDT), vol. 6, n 2, octubre 2014, pp. 147-174; A.-L. Calvo Caravaca/ J. Carrascosa González, "La gestación por sustitución y derecho internacional privado. Más allá del Tribunal Supremo y del Tribunal Europeo de Derechos Humanos", Cuadernos de Derecho Transnacional (CDT), vol. 7, n 2, octubre 2015, pp. 45-113; A. AzNAR Domingo, "Regulación y análisis de la gestación por sustitución en España", Diario La Ley, Wolters Kluwer, n 9099, 14 diciembre 2017. pp. 1-24; J. Carrascosa González, "Filiación natural”, en A.-L. Calvo Caravaca/ J. Carrascosa González (dirs.), Tratado de Derecho Internacional Privado, Tomo II, Tirant lo Blanch, Valencia, 2020, pp. 1865-1903.

${ }^{13}$ R. Bercovitz Rodríguez-Cano, "Hijos made in California", Aranzadi Civil Revista Doctrinal, no 3 (Tribuna), AranzadiWestlaw, Pamplona, 2009, p. 1; A. QuiÑones EsCÁMEZ, "Doble filiación paterna de gemelos nacidos en el extranjero mediante maternidad subrogada. En torno a la RDGRN de 18 de febrero de 2009", Indret, n 3, Editorial Universitat Pompeu Fabra, Barcelona, julio 2009, p. 4; A.-L. Calvo Caravaca/ J. CARrascosa GonzÁlez, "Gestación por sustitución y Derecho internacional privado: Consideraciones en torno a la Resolución de la Dirección General de los Registros y del Notariado de 18 de febrero de 2009", Cuadernos de Derecho Transnacional (CDT), vol. 1, nº 2, octubre 2009, p. 295; S. VILAR GonzÁLez, "Situación actual de la gestación por sustitución", Revista de Derecho UNED, n 14, 2014, p. 920; A. AzNAR Domingo, "Regulación y análisis de la gestación por sustitución en España”, Diario La Ley, Wolters Kluwer, n 9099, 14 diciembre 2017, p. 8.

${ }^{14} \mathrm{La}$ afirmación de que los menores son hijos biológicos de la pareja ha sido realizada por diversos autores (vid. A. QUIÑONES ESCÁMEZ, "Doble filiación paterna de gemelos nacidos en el extranjero mediante maternidad subrogada. En torno a la RDGRN de 18 de febrero de 2009”, Indret, n 3, Editorial Universitat Pompeu Fabra, Barcelona, julio 2009, p. 5; A.-L. CALVO Caravaca/ J. Carrascosa GonzÁlez, "Gestación por sustitución y Derecho internacional privado: Consideraciones en torno a la Resolución de la Dirección General de los Registros y del Notariado de 18 de febrero de 2009", Cuadernos de Derecho Transnacional (CDT), vol. 1, n 2, octubre 2009, p. 297). Sin embargo, el Tribunal Supremo en respuesta al recurso de casación planteado por los padres comitentes, así como en un Auto posterior, señala que no ha resultado probado que alguno de los padres comitentes aportara sus gametos, ya que aunque sí que se menciona en las alegaciones, sin embargo, no se concreta cuál de los padres lo habría aportado, ni menos aún se prueba cuál es el padre biológico de cada uno de los niños (STS (Sala de lo Civil) núm. 835/2013, de 6 de febrero de 2014 (RJ/2014\833) (ECLI:ES:TS:2014:247); Auto TS (Sala de lo Civil) de 2 febrero de 2015 (RJ 2015\141)). Así también lo constata L. ÁlvareZ DE Toledo al afirmar que "cuando, al hilo de las valiosas -pero objetables- enseñanzas del Tribunal Supremo, sostengamos nuestra opinión fundada acerca de si es contraria al orden público internacional español, la decisión extranjera de inscribir un niño como hijo de quienes, ni lo han alumbrado, ni consta con certeza hayan participado con sus propios cuerpos en el proceso biológico de la concepción, la gestación y el parto" (L. Álvarez DE Toledo, "El futuro de la maternidad subrogada en España: entre el fraude de Ley y el correctivo de orden público internacional", Cuadernos de Derecho Transnacional (CDT), vol. 6, n² 2, octubre 2014, p. 9).

${ }^{15}$ A. Aznar Domingo, "Regulación y análisis de la gestación por sustitución en España", Diario La Ley, Wolters Kluwer, no 9099,14 diciembre 2017, p. 8.

${ }^{16}$ Resolución de la DGRN de 18 de febrero de 2009, Boletín del Ministerio de Justicia, Núm. 2104 (Fecha de edición: 15 de marzo de 2010, con las Resoluciones de 07/01/2009 a 20/02/2009).

${ }^{17}$ A. Aznar Domingo, "Regulación y análisis de la gestación por sustitución en España”, Diario La Ley, Wolters Kluwer, $n^{\circ} 9099,14$ diciembre 2017, p. 8. 
se sustenta en la decisión judicial californiana que establece la filiación, y esta no se acompaña ${ }^{18}$. Por lo tanto, dichos autores señalan que habría tenido que exigirse el reconocimiento previo de la sentencia para pasar el control de legalidad, dada la relación de causa-efecto existente entre ambos documentos, requisito que finalmente se incluyó en la Instrucción de la DGRN de 5 de octubre de $2010^{19}$.

Pero lo más relevante de la misma, es que para la DGRN dicha solución no vulnera el orden público internacional, evita la discriminación y protege el interés superior del menor. Por supuesto, la DGRN añade que el principio de "interés superior del menor" debe estar por encima de cualquier otra consideración ${ }^{20}$.

9. Sin embargo, el Ministerio Fiscal impugnó dicha resolución porque se infringía el art. 10 de la Ley 14/2006, de 26 de mayo, sobre técnicas de reproducción humana asistida, que establecía la nulidad de pleno derecho del contrato de gestación por sustitución, y que la filiación de los hijos nacidos por gestación por sustitución venía determinada por el parto, quedando a salvo la posible acción de reclamación de la paternidad respecto del padre biológico ${ }^{21}$. Consideraba el Ministerio Fiscal que el contenido de la resolución de la DGRN era contrario al orden público internacional español y que, por tanto, no procedía la inscripción de la filiación en ella acordada ${ }^{22}$.

Tras varias vicisitudes y batallas judiciales y registrales, finalmente los padres recurren ante el Tribunal Supremo, solicitando la inscripción de la certificación registral californiana de nacimiento de los niños a favor de los padres comitentes. Se debe añadir que se dictaron distintas resoluciones y sentencias en torno al mismo, en las que la filiación y la inscripción de la filiación son determinadas de manera diferente en función del órgano o tribunal que conoce del asunto.

Sin embargo, los magistrados del Tribunal Supremo, en su Sentencia del 6 de febrero de 2014, resolvieron en el mismo sentido que lo hizo tanto el Juzgado como la Audiencia Provincial de Valencia ${ }^{23}$.

\section{A) El orden público internacional español}

10. En los antecedentes del caso, ya señala el Alto Tribunal que los recurrentes no han aportado al proceso, ni el contrato de gestación por sustitución, ni la sentencia del tribunal californiano atribuyendo la paternidad a los padres comitentes, aunque estos han admitido en sus alegaciones la existencia de dicho contrato, así como la existencia de la sentencia californiana, exigida por el Código de Familia de California ${ }^{24}$.

El Tribunal Supremo acierta al señalar que la técnica jurídica que se debe utilizar no es la del conflicto de leyes, sino la del reconocimiento, puesto que existe ya una decisión de la autoridad administrativa del Registro Civil de California, cuando se inscribió el nacimiento de los niños y se determinó

\footnotetext{
${ }^{18}$ A. QuiÑones Escámez, "Doble filiación paterna de gemelos nacidos en el extranjero mediante maternidad subrogada. En torno a la RDGRN de 18 de febrero de 2009”, Indret, n 3, Editorial Universitat Pompeu Fabra, Barcelona, julio 2009 , p. 14.

${ }^{19} \mathrm{Vid}$. A. QuiÑones EsCÁMEZ, "Doble filiación paterna de gemelos nacidos en el extranjero mediante maternidad subrogada. En torno a la RDGRN de 18 de febrero de 2009”, Indret, no 3, Editorial Universitat Pompeu Fabra, Barcelona, julio 2009 , pp. $13-15$.

${ }^{20}$ FD V Resolución de la DGRN de 18 de febrero de 2009, Boletín del Ministerio de Justicia, Núm. 2104 (Fecha de edición: 15 de marzo de 2010, con las Resoluciones de 07/01/2009 a 20/02/2009). Vid. A.-L. Calvo Caravaca/ J. CARrascosa GonZÁlez, "Gestación por sustitución y Derecho internacional privado: Consideraciones en torno a la Resolución de la Dirección General de los Registros y del Notariado de 18 de febrero de 2009”, Cuadernos de Derecho Transnacional (CDT), vol. 1, n 2, octubre 2009, pp. 310-315.

${ }^{21}$ Ley 14/2006, de 26 de mayo, sobre técnicas de reproducción humana asistida, BOE núm. 126, 27 mayo 2006. En adelante, se denominará Ley 14/2016. La gestación por sustitución o maternidad subrogada no se admite en nuestra legislación, al igual que sucede con otras figuras jurídicas como son los matrimonios poligámicos, los cuales son válidos en otros ordenamientos, pero no lo son en el ordenamiento español. Vid. M.-J. Castellanos Ruiz, "Denegación de la nacionalidad española por poligamia: análisis jurisprudencial”, Cuadernos de Derecho Transnacional (CDT), vol. 10, no 1, marzo 2018, pp. 94-126.

${ }^{22}$ FD I.4 STS (Sala de lo Civil) núm. 835/2013, de 6 de febrero de 2014 (RJ/2014\833) (ECLI:ES:TS:2014:247).

${ }^{23}$ STS (Sala de lo Civil) núm. 835/2013, de 6 de febrero de 2014 (RJ 2014\833) (ECLI:ES:TS:2014:247). Vid. SJPI Valencia (núm. 15) núm. 193/2010 de 15 septiembre (AC\2010\1707); SAP Valencia núm. 826/2011 de 23 noviembre (AC\2011\1561).

${ }^{24}$ FD I.7 STS (Sala de lo Civil) núm. 835/2013, de 6 de febrero de 2014 (RJ/2014\833) (ECLI:ES:TS:2014:247).
} 
una filiación a favor de los padres comitentes, de acuerdo con las leyes californianas. La cuestión a resolver, según señala el Tribunal Supremo, es si esa decisión extranjera puede ser reconocida, y desplegar sus efectos, en concreto la determinación de la filiación a favor de los padres comitentes, en el sistema jurídico español ${ }^{25}$.

Efectivamente podría cuestionarse si la decisión de autoridad extranjera a reconocer es la de la práctica del asiento registral en el que aparece recogida la filiación de los menores o la de la sentencia previa dictada por la autoridad judicial que determinó tal filiación con base en el contrato de gestación por sustitución y por aplicación de las leyes de California ${ }^{26}$. Sin embargo, el Tribunal Supremo señala que este problema no ha sido planteado a lo largo del litigio, y no es imprescindible abordarlo para decidir las cuestiones importantes que son objeto del recurso ${ }^{27}$.

11. La forma en que el Tribunal Supremo ha procedido al reconocimiento del título extranjero, es la prevista en el art. 85 RRC (Reglamento de la Ley del Registro Civil) en relación al último inciso del art. $81 \mathrm{RRC}^{28}$. El control consiste en que la certificación del Registro extranjero sea regular y auténtica, "de modo que el asiento que certifica, en cuanto a los hechos de que da fe, tenga garantías análogas a las exigidas para la inscripción por la Ley española" ${ }^{29}$. Pero también ha de extenderse a que no haya duda de la realidad del hecho inscrito y de su legalidad conforme a la Ley española, tal y como lo exige el art. 23 de la Ley del Registro Civil (LRC), al que sirven de desarrollo los preceptos reglamentarios $\operatorname{citados}^{30}$. Así que en principio, según el Tribunal Supremo, el control no debe limitarse a los aspectos formales, sino que tiene que extenderse a cuestiones de fondo ${ }^{31}$. Sin embargo, la remisión a la "ley española" ha de entenderse efectuada al orden público internacional español ${ }^{32}$.

Dentro del orden público internacional español están las normas que regulan los aspectos fundamentales de la familia, y dentro de ella, los que sostienen la filiación, pero también el art. 10 Ley

${ }^{25}$ FD III.2 STS (Sala de lo Civil) núm. 835/2013, de 6 de febrero de 2014 (RJ/2014\833) (ECLI:ES:TS:2014:247). Vid. L. Álvarez De Toledo, "El futuro de la maternidad subrogada en España: entre el fraude de Ley y el correctivo de orden público internacional", Cuadernos de Derecho Transnacional (CDT), vol. 6, no 2, octubre 2014, p. 15; A.-L. Calvo CaravaCa/ J. Carrascosa GonzÁlez, "La gestación por sustitución y derecho internacional privado. Más allá del Tribunal Supremo y del Tribunal Europeo de Derechos Humanos", Cuadernos de Derecho Transnacional (CDT), vol. 7, n 2, octubre 2015, p. 67-69; J. Carrascosa González, "Filiación natural", en A.-L. Calvo Caravaca/ J. Carrascosa González (dirs.), Tratado de Derecho Internacional Privado, Tomo II, Tirant lo Blanch, Valencia, 2020, p. 1889.

${ }^{26}$ En este sentido, los profesores A.-L. Calvo Caravaca/ J. Carrascosa González señalan que el Tribunal Supremo no exige una sentencia para conseguir la inscripción de los menores en el Registro Civil, si bien lo que dice el Tribunal Supremo es que las partes no aportan la sentencia californiana para lograr el reconomimiento de la sentencia, así que no entran a valorar esta cuestión, sino que se centran en el objeto del recurso (A.-L. CALVo CARAVACA/ J. CARrascosa GonzÁlez, "La gestación por sustitución y derecho internacional privado. Más allá del Tribunal Supremo y del Tribunal Europeo de Derechos Humanos", Cuadernos de Derecho Transnacional (CDT), vol. 7, $\mathrm{n}^{\circ}$ 2, octubre 2015, p. 53). El hecho de que no sea necesaria la sentencia extranjera donde consta la filiación de los menores, para lograr la inscripción en el Registro Civil español, en contra de lo señalado por la Instrucción de la DGRN de 5 de octubre de 2010, ha sido aplaudido por parte de la doctrina (A. HERNÁNDEZ Rodríguez, "La determinación de la filiación de los nacidos en el extranjero mediante gestación por sustitución: ¿Hacia una nueva regulación en España?", Cuadernos de Derecho Transnacional (CDT), vol. 6, nº 2, octubre 2014, p. 157; A.-L. CALVO Caravaca/ J. Carrascosa González, "La gestación por sustitución y derecho internacional privado. Más allá del Tribunal Supremo y del Tribunal Europeo de Derechos Humanos", Cuadernos de Derecho Transnacional (CDT), vol. 7, $\mathrm{n}^{\circ}$ 2, octubre 2015, p. 69; J. Carrascosa GonzÁlez, "Filiación natural”, en A.-L. Calvo Caravaca/ J. CARrascosa González (dirs.), Tratado de Derecho Internacional Privado, Tomo II, Tirant lo Blanch, Valencia, 2020, pp. 1889-1890.

${ }^{27}$ FD III.2 STS (Sala de lo Civil) núm. 835/2013, de 6 de febrero de 2014 (RJ/2014\833) (ECLI:ES:TS:2014:247).

${ }^{28}$ Vid. arts. 81 y 85 Decreto de 14 de noviembre de 1958 por el que se aprueba el Reglamento de la Ley del Registro Civil, BOE núm. 296, 11 diciembre 1958.

${ }^{29}$ FD III.2 STS (Sala de lo Civil) núm. 835/2013, de 6 de febrero de 2014 (RJ 2014\833) (ECLI:ES:TS:2014:247).

${ }^{30}$ Art. 23 de la vigente Ley del Registro Civil (Ley de 8 de junio de 1957 sobre el Registro Civil, BOE núm. 151, 10 junio 1957). La nueva Ley del 2011 no entrará en vigor hasta el 30 de junio de 2020.

${ }^{31}$ FD III.3 STS (Sala de lo Civil) núm. 835/2013, de 6 de febrero de 2014 (RJ/20141833) (ECLI:ES:TS:2014:247). En este sentido, se parece bastante a la solución adoptada por la DGRN en la Resolución de 18 de febrero de 2009 sobre este mismo asunto.

${ }^{32}$ FD III.4 STS (Sala de lo Civil) núm. 835/2013, de 6 de febrero de 2014 (RJ 2014|833) (ECLI:ES:TS:2014:247). Vid. A. HERNÁNDEZ RodRÍGUEZ, "La determinación de la filiación de los nacidos en el extranjero mediante gestación por sustitución: ¿Hacia una nueva regulación en España?”, Cuadernos de Derecho Transnacional (CDT), vol. 6, nº 2, octubre 2014, p. 157. 
14/2006, que es la norma que regula la gestación por sustitución, forma parte del orden público internacional español ${ }^{33}$. El art. 10.2 establece que la filiación de los menores vendrá determinada por el parto, de forma que es la madre californiana, la madre gestante, a la que las normas españolas le atribuyen la filiación de los menores y la que debería aparecer en la certificación registral californiana.

En consecuencia, la cláusula de orden público internacional español impide considerar válido y ejecutar en España un contrato de gestación por sustitución, así como el reconocimiento de la decisión registral extranjera en lo que respecta a la filiación que en ella se determine ${ }^{34}$.

\section{B) El principio de "interés superior del menor"}

12. Finalmente, antes de establecer las costas y el fallo de la sentencia, el Tribunal Supremo se pronuncia sobre la posible vulneración del interés superior del menor recogido en el art. 3 de la Convención sobre los Derechos del Niño (CDN) y que alegan las partes ${ }^{35}$.

Señala al respecto el Alto Tribunal que este principio sirve para complementar las leyes, tanto en su aplicación como en su interpretación, de forma que la filiación deberá determinarse no sólo en atención a este principio sino también teniendo siempre presente la legislación del Ordenamiento Jurídico correspondiente. Es decir, la inscripción de los menores nacidos por maternidad subrogada que se realice quebrantando las normas también supone un perjuicio para el menor ${ }^{36}$. Por lo tanto, el principio de interés superior del menor no es el único que se debe tener en consideración, sino que se deben tener en cuenta otros principios como son el respeto a la dignidad e integridad moral de la mujer gestante, evitar la explotación del estado de necesidad en que pueden encontrarse mujeres jóvenes en situación de pobreza, o impedir la mercantilización de la gestación y de la filiación ${ }^{37}$.

13. Según el Tribunal Supremo, los menores no ven vulnerado su derecho a una identidad única, porque no tienen una vinculación efectiva con Estados Unidos, puesto que los padres comitentes se trasladan allí porque era posible celebrar un contrato de maternidad subrogada ${ }^{38}$. En las sentencias internacionales que se citan para apoyar la vulneración del interés superior de menor, García Avello y Grunkin-Paul, el Tribunal Supremo señala que los menores sí que tenían una vinculación efectiva con dos Estados distintos, como consecuenica de la diferente nacionalidad de sus padres o por ser distinto el país de residencia del país de nacionalidad ${ }^{39}$.

Pero, además, para el Tribunal Supremo el bien jurídico protegido, la inmutabilidad de los apellidos, es de "mucha menor importancia" que los protegidos por la prohibición de gestación por sustitu-

\footnotetext{
${ }^{33}$ Estos principios fundamentales que deben protegerse son: la dignidad de la persona (art. $10 \mathrm{CE}$ ), tanto de la mujer gestante como del hijo; la protección de la infancia (art. $39 \mathrm{CE}$ ); el derecho a la intimidad familiar (art. 18.1 CE); y el derecho a la integridad moral (art. 15 CE). Vid. FD III.5 y FD III.7 STS (Sala de lo Civil) núm. 835/2013, de 6 de febrero de 2014 (RJ 2014\833) (ECLI:ES:TS:2014:247). También es considerado un acierto por parte de la doctrina que el art. 10 Ley 14/2006 no se haya aplicado como una norma internacionalmente imperativa, sino como una norma que forma parte del orden público internacional español (A.-L. Calvo Caravaca/ J. Carrascosa GonzÁlez, "La gestación por sustitución y derecho internacional privado. Más allá del Tribunal Supremo y del Tribunal Europeo de Derechos Humanos", Cuadernos de Derecho Transnacional $(C D T)$, vol. $7, \mathrm{n}^{\circ}$ 2, octubre 2015, pp. 70-71).

${ }^{34}$ FD III.11 STS (Sala de lo Civil) núm. 835/2013, de 6 de febrero de 2014 (RJ 2014\833) (ECLI:ES:TS:2014:247).

${ }^{35}$ FD V STS (Sala de lo Civil) núm. 835/2013, de 6 de febrero de 2014 (RJ/2014\833) (ECLI:ES:TS:2014:247). En cuanto a que la denegación de la inscripción de nacimiento y filiación a favor de dos varones resulta discriminatorio (art. 7.3 Ley 14/2006), el Tribunal Supremo establece que no lo es porque la desigualdad sustancial entre los supuestos de hecho excluye la existencia de un trato discriminatorio (FD IV STS (Sala de lo Civil) núm. 835/2013, de 6 de febrero de 2014 (RJ\2014\833) (ECLI:ES:TS:2014:247)). Argumento que también fue utilizado por los padres comitentes en los recursos presentados ante las instancias inferiores y fue rebatido en el mismo sentido. Vid. art. 3 de la Convención sobre los derechos del niño hecha en Nueva York el 20 de noviembre de 1989 (BOE núm. 313, 31 diciembre 1990), en vigor para España desde el 5 de enero de 1991.

${ }^{36}$ FD V.8 STS (Sala de lo Civil) núm. 835/2013, de 6 de febrero de 2014 (RJ 2014|833) (ECLI:ES:TS:2014:247).

${ }^{37}$ FD V.7 STS (Sala de lo Civil) núm. 835/2013, de 6 de febrero de 2014 (RJ 2014\833) (ECLI:ES:TS:2014:247).

${ }^{38}$ FD V.9 STS (Sala de lo Civil) núm. 835/2013, de 6 de febrero de 2014 (RJ/2014\833) (ECLI:ES:TS:2014:247).

${ }^{39}$ Vid. STJUE 2 octubre 2003, García Avello, C-148/02 (ECLI:EU:C:2003:539); STJUE 14 octubre 2008, Grunkin-Paul, C-353/06 (ECLI:EU:C:2008/559).
} 
ción. Todo ello, a pesar de que la DGRN en la Resolución de 18 de febrero de 2009, había señalado que el derecho a la identidad única del menor implica exigir que el nombre y apellidos, así como la filiación de un menor, otorgados en un Estado sean respetados por el Derecho de los demás Estados ${ }^{40}$.

14. Con la denegación del reconocimiento de la filiación establecida por autoridades californianas tampoco se vulnera el derecho a la vida privada y familiar reconocido en el art. 8 del CEDH, tal y como señala el Tribunal Supremo ${ }^{41}$.

En la jurisprudencia del TEDH, Wagner y otro c. Luxemburgo, se justifica la intromisión en el derecho a la vida privada y familiar, porque: por un lado, está prevista en la ley, ya que en el reconocimiento de decisiones extranjeras se exige que no se vulnere el orden público internacional; y por otro lado, porque se protege el propio interés del menor, se respeta a la dignidad e integridad moral de la mujer gestante, se evita la explotación de mujeres jóvenes en situación de pobreza, o se impide la mercantilización de la gestación y de la filiación ${ }^{42}$.

15. La última cuestión que ha de abordarse es la de la desprotección en que se dejaría a los menores, alegada por los padres comitentes ${ }^{43}$. Sin embargo, esta protección debe realizarse teniendo en cuenta las normas españolas, así como la jursiprudencia que las interpreta.

En este sentido, el TEDH, al interpretar el art. 8 del Convenio, es decir, el derecho al respeto a la vida privada y familiar, señala que si existe una relación de familia con un niño, el Estado debe actuar para permitir que ese vínculo se desarrolle y para proteger la integración del niño en su familia, tal y como se recoge en las sentencias Wagner y otro contra Luxemburgo y Harroudj contra Francia ${ }^{44}$. Pero, siguiendo con la jurisprudencia del Tribunal Supremo y del TEDH, si el núcleo familiar ya existe y si los menores tienen relaciones familiares "de facto" con los padres comitentes, se tendría que tener en cuenta este dato, para permitir el desarrollo y la protección de estos vínculos.

El Tribunal Supremo señala además que en el ordenamiento español existen diversas instituciones que permiten el desarrollo y la protección de estos vínculos. En primer lugar, el art. 10.3 de la Lay 14/2006, permite la reclamación de la paternidad respecto del padre biológico, por si alguno de los recurrentes lo fuera ${ }^{45}$. En segundo lugar, señala el Tribunal Supremo "figuras jurídicas como el acogimiento familiar o la adopción permiten la formalización jurídica de la integración real de los menores en tal núcleo familiar".

Por último, el Tribunal Supremo establece que, de conformidad con el art. 7.1 de la CDN, el niño ha de ser inscrito inmediatamente después de su nacimiento y tendrá derecho desde que nace a un nombre y a una nacionalidad, por lo que la denegación de reconocimiento de la certificación registral de California afectará exclusivamente a la filiación en ella determinada, pero no al resto de su contenido.

16. Concluye el Tribunal Supremo, que no se consigue garantizar la protección del interés de los menores, mediante la celebración de un contrato de gestación por sustitución y a través de la filiación a favor de los padres comitentes que prevé la legislación de California; sino que habrá que partir, si es verdad que esto es así, de la ruptura de todo vínculo de los menores con la mujer californiana que les

${ }^{40}$ Vid. A.-L. Calvo Caravaca/ J. Carrascosa González, "Gestación por sustitución y Derecho internacional privado: Consideraciones en torno a la Resolución de la Dirección General de los Registros y del Notariado de 18 de febrero de 2009”, Cuadernos de Derecho Transnacional (CDT), vol. 1, nº 2, octubre 2009, pp. 312-314.

${ }^{41}$ FD V.10 STS (Sala de lo Civil) núm. 835/2013, de 6 de febrero de 2014 (RJ/2014\833) (ECLI:ES:TS:2014:247).

${ }^{42}$ STEDH 28 junio 2007, Wagner y otro c. Luxemburgo, 76240/01 (JUR\2007\147388).

${ }^{43}$ FD V.11 STS (Sala de lo Civil) núm. 835/2013, de 6 de febrero de 2014 (RJ 2014\833) (ECLI:ES:TS:2014:247).

${ }^{44}$ STEDH 28 junio 2007, Wagner y otro c. Luxemburgo, 76240/01 (JUR\2007\147388); STEDH 4 octubre 2012, Harroudj c. Francia, 43631/09 (TEDH\2012\89).

${ }^{45}$ El TS recuerda que el objeto del recurso no era adoptar una decisión sobre la integración de los menores en la familia constituida por los padres comitentes, sino el reconocimiento de la filiación fijada en el registro de California. También señala que no ha quedado probado si alguno de los comitentes aportó sus gametos, puesto que, aunque se menciona en las alegaciones, ni se concreta cuál de ellos los habría aportado, ni menos aún se prueba cual sería el padre biológico de cada uno de los menores (FD V.11 STS (Sala de lo Civil) núm. 835/2013, de 6 de febrero de 2014 (RJ\2014\833) (ECLI:ES:TS:2014:247)). 
dio a luz, de la existencia en la actualidad de un núcleo familiar formado por los menores y los padres comitentes, y la paternidad biológica de alguno de ellos respecto de tales menores ${ }^{46}$.

Teniendo en cuenta la interpretación que el TEDH ha realizado del derecho al respeto a la vida privada y familiar (art. $8 \mathrm{CEDH}$ ), el Tribunal Supremo insta al Ministerio Fiscal, a que "ejercite las acciones pertinentes para determinar en la medida de lo posible la correcta filiación de los menores, y para su protección, tomando en consideración, en su caso, la efectiva integración de los mismos en un núcleo familiar "de facto"' 47 . Lo cual implica determinar primero, si alguno de los padres comitentes es el padre biológico, y segundo, proceder a la adopción o al acogimiento para lograr la protección de los vínculos familiares que ya existen "de facto" entre los menores y sus padres.

17. No obstante, con independencia del voto particular que viene a dar la razón a los recurrentes, parte de la doctrina opina que en la sentencia del 6 de febrero de 2014 el Tribunal Supremo no ha tenido en cuenta "el interés superior del menor", sino que al contrario, el principio del "interés superior del menor" no es "superior", sino "inferior", ya que hay otros intereses que prevalecen sobre el mismo ${ }^{48}$. La doctrina señala que es un acierto por parte del Tribunal Supremo la admisión de que el núcleo social formado por los padres comitentes españoles y los menores nacidos en el extranjero mediante gestación por sustitución constituyen una "familia" y así debe ser calificado. Esta familia merece una protección por parte del sistema jurídico español, pues así lo indica el art. $39 \mathrm{CE}^{49}$.

\section{Auto del Tribunal Supremo de 2 de febrero de 2015}

18. Se debe destacar que la sentencia del Tribunal Supremo es anterior a las sentencias de los asuntos Mennesson y Labassee dictadas por el Tribunal Europeo de Derechos Humanos -que serán explicadas posteriomente y en las que se obliga a Francia al reconocimiento de la filiación de los menores nacidos en el extranjero por medio de un contrato de gestación por sustitución-, con una diferencia de alrededor de cuatro meses, por lo que la doctrina del TEDH recogida en ambas sentencias, dictadas el 26 de junio de 2014, no pudo ser tenida en cuenta por el Tribunal Supremo, en su sentencia sobre los "niños de California" de 6 de febrero de 2014.

Sin embargo, las sentencias del TEDH fueron muy importantes y han tenido una influencia en el resto de países como Italia que también prohíben y sancionan la gestación por sustitución, tal y como lo hacen la normativa francesa y española. Tal es así, que la DGRN dictó con fecha 11 de julio de 2014 una Circular por la que se reconocía plena validez y vigencia a la Instrucción de la DGRN de 5 de octubre de 2010 en aras a la protección del interés superior del menor, practicándose las inscripciones por los encargados del Registro Civil conforme a las directrices fijadas en la Instrucción ${ }^{50}$. En este sentido, la DGRN desarrolló, mientras se resolvía el litigio sobre los "niños de Califormia”, una Instrucción sobre

\footnotetext{
${ }^{46}$ Concretamente el art. 10.3 de la Ley 14/2006 sobre técnicas de reproducción humana asistida (BOE núm. 126, 27 mayo 2006), permite la reclamación de la paternidad respecto del padre biológico, por si alguno de los recurrentes lo fuera.

${ }^{47}$ FD V.12 STS (Sala de lo Civil) núm. 835/2013, de 6 de febrero de 2014 (RJ 2014|833) (ECLI:ES:TS:2014:247).

${ }^{48}$ L. Álvarez DE Toledo, "El futuro de la maternidad subrogada en España: entre el fraude de Ley y el correctivo de orden público internacional”, Cuadernos de Derecho Transnacional (CDT), vol. 6, no 2, octubre 2014, pp. 30-33; A.-L. CALVO Caravaca/ J. Carrascosa GonzÁlez, "La gestación por sustitución y derecho internacional privado. Más allá del Tribunal Supremo y del Tribunal Europeo de Derechos Humanos", Cuadernos de Derecho Transnacional (CDT), vol. 7, $\mathrm{n}^{\circ}$ 2, octubre 2015, p. 74. Para un análisis del "interés inferior del menor" vid. A.-L. Calvo Caravaca/ J. Carrascosa González, "La gestación por sustitución y derecho internacional privado. Más allá del Tribunal Supremo y del Tribunal Europeo de Derechos Humanos", Cuadernos de Derecho Transnacional (CDT), vol. 7, nº 2, octubre 2015, pp. 78-92.

${ }^{49}$ A.-L. Calvo Caravaca/ J. Carrascosa González, "La gestación por sustitución y derecho internacional privado. Más allá del Tribunal Supremo y del Tribunal Europeo de Derechos Humanos", Cuadernos de Derecho Transnacional (CDT), vol. 7, no 2, octubre 2015, p. 70; J. Carrascosa González, "Filiación natural”, en A.-L. Calvo Caravaca/ J. Carrascosa GonzÁlez (dirs.), Tratado de Derecho Internacional Privado, Tomo II, Tirant lo Blanch, Valencia, 2020, p. 1890.

${ }^{50}$ A. Aznar Domingo, "Regulación y análisis de la gestación por sustitución en España", Diario La Ley, Wolters Kluwer, n 9099, 14 diciembre 2017, p. 13; M.-J. CABEZUDo BAJO, "Avances hacia una regulación de la gestación por sustitución en España en base al modelo regulado por el Estado de California", Revista de Derecho y Genoma Humano. Genética, Biotecnología y Medicina Avanzada, Dykinson, no 46, enero-junio 2017, p. 109.
} 
régimen registral de la filiación de los nacidos mediante gestación por sustitución, con fecha del 5 de octubre de $2010^{51}$. Dicha Instrucción en la práctica, exige que los interesados obtengan una sentencia judicial extranjera en la que conste la filiación de los menores a favor de los padres comitentes. Esta sentencia debe presentarse para su exequatur en España, que se rige por los convenios internacionales vigentes para España o en su defecto, por los arts. 41-61 LCJIMC (Ley de cooperación jurídica internacional en materia civil $)^{52}$.

19. Además, los padres comitentes de los "niños de California" presentaron un incidente de nulidad actuaciones contra la Sentencia de 6 de febrero de 2014, por haberse vulnerado tres derechos fundamentales: el derecho a la tutela judicial efectiva, el derecho a la igualdad sin discriminación y el derecho a la intimidad familiar. Pero antes de resolverse el incidente de nulidad de actuaciones promovido contra dicha sentencia por los padres comitentes, el TEDH dictó las sentencias de los casos Mennesson y Labassee.

Dada la transcendencia jurídica de dicha jurisprudencia, el Tribunal Supremo consideró que el incidente de nulidad de actuaciones era el medio más idóneo para valorar si se había producido una vulneración de los derechos fundamentales conforme a la interpretación realizada de los mismos por parte del TEDH ${ }^{53}$. Además, se acordó dar traslado a las partes para que alegaran lo que considerasen oportuno en relación con los pronunciamientos de las referidas sentencias. Los recurrentes, una vez que señalaron la transcendencia de las sentencias de los casos Mennesson y Labassee, subrayaron que el TEDH, en estas sentencias: "critica especificamente las soluciones que otorgan los tribunales franceses a los litigantes: reconocimiento de paternidad, adopción, o notoriedad de estado. Es decir, las mismas soluciones que se sugiere a los litigantes españoles. La crítica versa sobre la grave restricción sobre la identidad y el derecho fundamental a la vida privada de los menores" ${ }^{\prime 4}$.

20. Así pues, el Tribunal Supremo, por medio de Auto de fecha 2 de febrero de 2015, resolviendo el incidente de nulidad de actuaciones que se planteó frente a la Sentencia del TS de 6 de febrero de 2014 dictaminó, que a diferencia de lo ocurrido con las sentencias del TEDH, casos Mennesson y Labassee, no se había producido una vulneración del derecho a la identidad, ni del derecho al respeto de la vida privada de los menores por su no inscripción en el Registro Civil español ${ }^{55}$.

El Tribunal Supremo señala que en los casos Mennesson y Labassee, lo que lleva al TEDH a considerar vulnerado el art. 8 del $\mathrm{CEDH}$, en lo relativo al derecho a la vida privada de los menores, es que el ordenamiento francés, considerando que existe un fraude a la ley, no permita el reconocimiento de la filiación entre los matrimonios comitentes y las niñas gestadas por subrogación por ningún medio (transcripción de actas de nacimiento, filiación biológica paterna, adopción, posesión de estado), y sobre todo, que no admita el reconocimiento de la filiación paterna biológica ${ }^{56}$. Según el TEDH, el que los tribunales franceses protejan intereses legítimos como la protección de la salud y la protección de los

${ }^{51}$ Instrucción de 5 de octubre de 2010, de la Dirección General de los Registros y del Notariado, sobre régimen registral de la filiación de los nacidos mediante gestación por sustitución, BOE núm. 243, 7 octubre 2010.

${ }^{52}$ Arts. 41-61 Ley de cooperación jurídica internacional en materia civil, BOE núm. 182, 31 julio 2015. Se exige el exequatur de la sentencia extranjera, siempre y cuando se trate de un procedimiento jurisdiccional contencioso. Sin embargo, si la resolución extranjera ha sido dictada como consecuencia de un "procedimiento análogo a uno español de jurisdicción voluntaria", no será necesario acudir a un procedimiento judicial por homologación previo a la inscripción registral, sino que el Encargado del Registro Civil deberá proceder a controlar incidentalmente el reconocimiento de la resolución judicial, que consistirá en acreditar varios extremos. Vid. A.-L. Calvo Caravaca/ J. Carrascosa González, "Notas críticas en torno a la Instrucción de la Dirección General de los Registros y del Notariado de 5 octubre 2010 sobre régimen registral de la filiación de los nacidos mediante gestación por sustitución”, Cuadernos de Derecho Transnacional (CDT), vol. 3, nº 1, marzo 2011, p. 249; E. LAMm, Gestación por sustitución. Ni maternidad subrogada, ni vientres de alquiler, Publicacions i Edicions de la Universitat de Barcelona, Barcelona, 2013, p. 87.

${ }^{53}$ FD VI.1 Auto TS (Sala de lo Civil) de 2 febrero de 2015 (RJ $\left.2015 \backslash 141\right)$.

${ }^{54}$ FD. VI.9 Auto TS (Sala de lo Civil) de 2 febrero de 2015 (RJ $2015 \backslash 141$ ).

${ }^{55}$ Auto TS (Sala de lo Civil) de 2 febrero de 2015 (RJ $2015 \backslash 141$ ).

${ }^{56}$ Para el Tribunal Supremo, los recurrentes se equivocan en la interpretación de las sentencias del TEDH (FD. VI.9 Auto TS (Sala de lo Civil) de 2 febrero de 2015 (RJ 2015\141)). 
derechos y libertades de los demás (tanto del niño como de la madre gestante, según el ordenamiento jurídico francés), provoca que no se cumpla con el interés superior del menor, que trae consigo una incertidumbre que afecta tanto a su identidad, de la que la filiación es un aspecto fundamental, como a la posibilidad de adquirir la nacionalidad francesa y de heredar como hijo, por lo que "el Estado francés habría ido más allá del margen de apreciación de lo que es necesario para una sociedad democrática

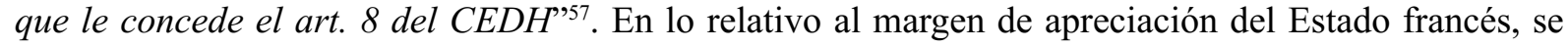
volverá a incidir al tratar los asuntos Mennesson y Labassee en el epígrafe correspondiente.

No obstante, el Alto Tribunal entiende que en las sentencias europeas se planteaba un supuesto distinto al que se dio en España, puesto que las resoluciones de nuestro país permitían la determinación de la filiación paterna de los padres comitentes, si efectivamente habían aportado el material genético, así como la adopción o acogimiento por parte del otro cónyuge, si se verificaba que de los padres comitentes y los niños formaban un núcleo familiar "de facto"; lo cual no fue permitido por los tribunales franceses $^{58}$. También se reconocía la nacionalidad española de los menores, así como todos los derechos sucesorios correspondientes -eso sí una vez determinada la filiación conforme a las leyes españolas-, a diferencia de los supuestos franceses ${ }^{59}$.

21. Con este auto, el Tribunal Supremo resuelve que, conforme al ordenamiento jurídico español, los padres comitentes no pueden ser considerados nunca como padres de los menores nacidos mediante gestación por sustitución, al ser un contrato nulo de pleno derecho según el art. 10 de la Ley 14/2006. En primer lugar, la paternidad biológica es la cuestión decisiva que determina la relación de filiación, esencial para establecer la identidad del menor, según las normas de orden público del ordenamiento español y todo ello en aras del interés superior del menor.

En segundo lugar, el otro aspecto fundamental es el establecimiento de lazos filiales como consecuencia de la existencia de un núcleo familiar "de facto" en el que estén integrados los menores, el progenitor biológico y su cónyuge, como por ejemplo mediante la adopción, en la que el interés del menor se controla y protege por el juez que la constituye (art. 176 del Código Civil). Esta cuestión no ha sido la planteada en el proceso, cuestión que sí se resolvía en los asuntos Mennesson y Labassee ${ }^{60}$.

22. Por su parte, el voto particular recogido en dicho Auto del Tribunal Supremo considera que los niños están creciendo en un entorno familiar, con independencia de la nulidad del contrato y que, en este sentido, no están recibiendo una protección especial. Esto provoca una serie de consecuencias que son: (a) Se genera y seguirá generando incertidumbre jurídica mientras no se de respuesta a su solicitud de inscripción; (b) El modelo de protección actual tiene el grave efecto de retrasar una filiación que podía haber sido ya fijada definitivamente; (c) Cuando se está admitiendo la maternidad subrogada a través de circulares o instrucciones de la DGRN, que convierten la excepción de orden público en una cuestión formal ${ }^{61}$. Desde luego, no podemos estar más de acuerdo con el voto particular de dicho auto.

Por otro lado, a pesar de lo establecido por el Tribunal Supremo, tanto en el Auto de 2 de febrero de 2015, como en la Sentencia de 6 de febrero de 2014, la prestación por maternidad reconocida a los padres comitentes viene a dar ciertos efectos jurídicos a unos contratos que son nulos de pleno derecho. Cabe destacar otra Sentencia del Tribunal Supremo, de 16 de noviembre de 2016, que fue pionera en el sentido de reconocer la prestación de maternidad para los padres de los menores nacidos por maternidad subrogada $^{62}$. Esta resolución deja claro que la situación de los menores y, en concreto, sus derechos, no se pueden ver afectados por la nulidad del contrato de maternidad subrogada. Además, el Tribunal Supremo en esta sentencia del 2016 entiende que el principio del interés superior del menor debe in-

\footnotetext{
${ }^{57}$ FD. VI.9 Auto TS (Sala de lo Civil) de 2 febrero de 2015 (RJ $\left.2015 \backslash 141\right)$.

${ }^{58}$ FD. VI.10 Auto TS (Sala de lo Civil) de 2 febrero de 2015 (RJ $\backslash 2015 \backslash 141$ ).

${ }^{59} \mathrm{Idem}$.

${ }^{60} \mathrm{Idem}$.

${ }^{61}$ Desde luego la solución ofrecida no es rápida, porque hasta que no se determine la filiación de la forma prevista por el Tribunal Supremo, los menores no tendrán la nacionalidad española, ni derechos sucesorios como hijos (FD. VI.10 Auto TS (Sala de lo Civil) de 2 febrero de 2015 (RJ 2015\141)).

${ }^{62}$ STS (Sala de los Social) núm. 953/2016 de 16 noviembre (RJ\2016\6152).
} 
terpretarse para colmar las lagunas que puedan existir en nuestra legislación, haciendo referencia a la sentencia dictada el 6 de febrero de 2014.

Por último, en este mismo sentido, debe destacarse una sentencia reciente que falla de forma contraria al Tribunal Supremo, pero de conformidad con la línea interpretativa mantenida por el TEDH.

\section{Sentencia de la Audiencia Provincial de Islas Baleares de 27 de abril de 2021}

23. Se trata de una Sentencia de la Audiencia Provincial de Islas Baleares, de 27 de abril de 2021, que ha permitido que una mujer inscriba como hija suya a una niña gestada a través de un contrato de gestación por sustitución en Rusia ${ }^{63}$.

La Sala confirma la filiación materna de una menor que nació en Moscú de una mujer rusa, a la que le fueron implantadas células germinales femeninas y masculinas de donantes anónimos, de modo que la niña carecía de vínculo biológico con la demandante, mujer española, soltera, que era la madre comitente.

24. Con el fin de cumplir con los requisitos establecidos por la Instrucción de la DGRN de 5 de octubre de 2010 y poder realizar la inscripción de la filiación de la menor a su favor, la mujer española, demandó a los tribunales rusos, para obtener una sentencia que acreditara dicha filiación. Sin embargo, la madre comitente, vio desestimada su demanda ante los tribunales rusos, que no reconocieron la filiación de la menor a favor de la demandante, porque ya poseía una certificación de nacimiento en la que constaba como madre de la menor, que se había efectuado de acuerdo con la legislación rusa y que hacía innecesaria su intervención ${ }^{64}$.

En este sentido, la demandante acierta al iniciar una acción de filiación ex novo, puesto que no pudo obtener una sentencia rusa en la que constara la filiación y solicitar su reconocimiento, mediante la Instrucción de la DGRN del 5 de octubre de 2010. A pesar de que, de forma errónea, la demanda es estimada con base en la citada Instrucción y añade el tribunal que considera posible y procedente una aplicación atenuada del orden público español de acuerdo con el principio de preservación del superior interés del menor ${ }^{65}$. Se equivoca en los argumentos para admitir la demanda, en primer lugar, porque la Instrucción de la DGRN está prevista para procedimientos de reconocimiento de la filiación determinada en el extranjero en los supuestos en que además de la certificación registral extranjera, se debe aportar la sentencia.

En segundo lugar, porque la interpretación que hace del orden público atenuado es diferente de la que hace el Tribunal Supremo en la Sentencia de 6 de febrero de 2014. Señalaba el Tribunal Supremo en el asunto de los "niños de California" que el orden público internacional español se caracteriza por ser un orden público "atenuado", donde el grado de atenuación es menor, cuantos mayores son los vínculos sustanciales de la situación jurídica con España. En dicho caso, como el supuesto tenía fuertes vínculos con España, porque en California sólo se llevó a cabo el contrato de maternidad subrogada, el orden público internacional español no podía "atenuarse" ${ }^{66}$. Si bien, en nuestra opinión, el Tribunal Supremo está confundiendo el orden publico internacional "atenuado" con el orden público internacional de "proximidad"67. No obstante, si tuviéramos en cuenta la interpretación del Tribunal Supremo en el

\footnotetext{
${ }^{63}$ SAP Islas Baleares núm. 207/2021 de 27 abril (JUR\2021\163294).

${ }^{64}$ FD III SAP Islas Baleares núm. 207/2021 de 27 abril (JUR\2021\163294).

${ }^{65}$ FD II SAP Islas Baleares núm. 207/2021 de 27 abril (JUR\2021\163294).

${ }^{66}$ FD III.7 STS (Sala de lo Civil) núm. 835/2013, de 6 de febrero de 2014 (RJ/2014\833) (ECLI:ES:TS:2014:247).

${ }^{67}$ L. Álvarez DE Toledo, "El futuro de la maternidad subrogada en España: entre el fraude de Ley y el correctivo de orden público internacional", Cuadernos de Derecho Transnacional (CDT), vol. 6, n 2, octubre 2014, pp. 19-20. En relación con el orden público internacional de proximidad vid. A.-L. CAlvo Caravaca/ J. CARRASCosa GonzÁlez, "La gestación por sustitución y derecho internacional privado. Más allá del Tribunal Supremo y del Tribunal Europeo de Derechos Humanos", Cuadernos de Derecho Transnacional (CDT), vol. 7, n² 2, octubre 2015, p. 91. También, A. QuiÑones EscÁmEZ confunde o quizás mezcla el orden público internacional atenuado - que distingue efectos nucleares de periféricos- con el de proximidad (A. QUIÑONES EsCÁMEZ, "Doble filiación paterna de gemelos nacidos en el extranjero mediante maternidad subrogada. En torno a la RDGRN de 18 de febrero de 2009”, Indret, no 3, Editorial Universitat Pompeu Fabra, Barcelona, julio 2009, p. 19).
} 
asunto de la gestación por sustitución llevada a cabo en Rusia procedería la misma solución que en el caso de los "niños de California, de forma que no podría aplicarse un orden público atenuado, porque el supuesto tiene fuertes vínculos con España y en Rusia únicamente se ha llevado a cabo el contrato de gestación por sustitución.

25. En cualquier caso, la demandante lo que hizo es iniciar una acción de filiación, alegando entre otros argumentos posesión de estado. Si bien la posesión de estado fue rechazada por la Audiencia Provincial, porque, aunque ésta quedó acreditada por los hechos que se relatan, no bastaba por sí misma para obtener la filiación de acuerdo con lo dispuesto en el art. 131 del Código Civil, porque contravenía lo dispuesto en el art. 10.2 de la Ley 14/2006. Este argumenrto es un error del juez, puesto que, al tratarse de una filiación internacional, no procede la aplicación directa de la norma sustantiva española, sino que es de aplicación, el art. 9.4 CC, que es la norma de conflicto que regula la filiación internacional. Sólo en el caso de que dicha norma nos lleve a la ley española, podría ser de aplicación la ley española y aplicar así la Ley 14/2006, como efectivamente sucede en este caso, pues la niña tiene su residencia habitual en España, que es el primer punto de conexión del art. 9.4 CC.

En cualquier caso, la Audiencia Provincial de Islas Baleares, tras un análisis de la doctrina del Tribunal Supremo y del TEDH, especialmente de lo señalado en el Dictamen del TEDH de 10 de abril de 2.019 concluye que, de acuerdo con la evaluación de las circunstancias de cada caso, tiene que haber un mecanismo eficaz que permita reconocer la relación entre el niño y la madre comitente, lo antes posible y en todo caso cuando dicha relación se haya convertido en una realidad práctica. No obstante, este derecho no exige que dicho reconocimiento adopte la forma de inscripción en el registro, sino que la adopción puede cumplir este requisito siempre que las condiciones que la regulen sean adecuadas y el procedimiento permita tomar rápidamente una decisión; de modo que el niño no se encuentre durante un largo periodo de tiempo en una situación de inseguridad jurídica en cuanto a dicha relación; debiendo incluir estas condiciones una evaluación por parte de los tribunales del interés superior del menor a la vista de las circunstancias del caso $^{68}$.

Aunque el TEDH es consciente de los riesgos de abuso que implican los acuerdos de gestación por sustitución y la posibilidad de conocer el origen de la persona, termina concluyendo que el interés superior del niño también supone identificar jurídicamente a las personas responsables de su educación, de satisfacer sus necesidades y garantizar su bienestar, así como de asegurar que el menor crezca y se desarrolle en un entorno estable. Son estas las razones por las que el Tribunal considera que la imposibilidad general y absoluta de obtener el reconocimiento de la relación entre un niño nacido por medio de un contrato de gestación subrogada celebrado en el extranjero y la madre comitente es incompatible con el interés superior del niño ${ }^{69}$.

26. Sin embargo, en el caso sometido a la consideración de la Audiencia Provincial de Islas Baleares, no es posible acogerse a las vías sugeridas por el Tribunal Supremo en su Sentencia de 6 de febrero de 2014 para establecer la filiación entre la demandante y la menor, puesto que no existe padre biológico de la menor que sea pareja de la madre comitente y que, por tanto, pudiese reclamar la filiación, adoptando a la niña. Tampoco puede acudirse a la adopción, puesto que existe una diferencia de edad entre la menor y la madre comitente de casi cuarenta y siete años, que excede la diferencia de edad máxima entre adoptante y adoptado establecida imperativamente en el art. 175.1 del CC (cuarenta y cinco años). Y tampoco podría acogerse a las excepciones recogidas en el art. 176.2 del CC, concretamente la tercera, porque la menor no se encuentra en situación de guarda con fines de adopción, ni la figura de la tutela resulta compatible con la realidad de la situación familiar existente, vivida por la niña junto con su madre comitente desde su nacimiento ${ }^{70}$.

No obstante, considera la Audiencia Provincial en esta Sentencia de 27 de abril de 2021, que únicamente el mantenimiento de la menor en el entorno familiar en el que vive y que conoce, que es el

\footnotetext{
${ }^{68}$ FD IV y V SAP Islas Baleares núm. 207/2021 de 27 abril (JUR\2021\163294).

${ }^{69}$ FD V SAP Islas Baleares núm. 207/2021 de 27 abril (JUR\2021\163294).

${ }^{70}$ FD VI SAP Islas Baleares núm. 207/2021 de 27 abril (JUR\2021\163294).
} 
de la madre intencional y el establecimiento de la filiación pretendida, puede aportar a la niña la seguridad jurídica y estabilidad necesarias para que la menor pueda seguir desarrollándose con plena tranquilidad en todos los aspectos de su vida, físicos, intelectuales y emocionales. Por ello, acuerda proceder a la inscripción solicitada, atendiendo al principio de superior interés de la niña, que pasa por "dar carta de naturaleza y preservar la situación familiar que vive desde su nacimiento", teniendo en cuenta también la posesión de estado, lo cual favorece a la demandante ${ }^{71}$.

27. En definitiva, en esta sentencia pionera en España en materia de gestación por sustitución, el interés superior del menor prevalece sobre cualquier otra consideración, de forma que una vez analizado el caso concreto, es decir, que se ha observado que el contrato de gestación por sustitución ha cumplido con las garantías requeridas para las partes y la menor en el Estado de celebración, la autoridad de cada Estado tiene un margen de discrecionalidad limitado para proponer un mecanismo eficaz que permita reconocer la relación entre el niño y la madre comitente a la mayor brevedad posible. Como las soluciones ofrecidas por el Tribunal Supremo en su sentencia de 6 de febrero de 2014, no pueden aplicarse al asunto que se está dirimiendo, la única posibilidad es proceder a la inscripción de la filiación de la menor a favor de la madre comitente.

A raíz de esta sentencia, en materia de gestación por sustitución, se podría afirmar que existe un incipiente orden público europeo que prevalece sobre el orden público internacional, en este caso, del Estado español. Dicho orden público español estaría integrado no sólo por los principios recogidos en el Convenio Europeo de Derechos Humanos, como son el derecho al "respeto a la vida privada y familiar" (art. 8); sino por los principios contenidos en la Convención de los Derechos del Niño, concretamente el principio del "interés superior del menor" (art. 3) y el derecho a que el niño sea inscrito inmediatamente después de su nacimiento y el derecho a que tenga un nombre desde que nace y a adquirir una nacionalidad (art. 7.1).

\section{Orden público internacional en Francia en lo referente a la gestación por sustitución}

28. Para entender cuándo se activa la cláusula de orden público internacional francés, pero, sobre todo, para comprender cómo el TEDH limita la intervención de dicho orden público en los casos de gestación por sustitución, se estudiarán los asuntos Mennesson contra Francia y Labassee contra Francia.

Se trataba en ambos casos de dos matrimonios formados por ciudadanos franceses, marido y mujer, que, como consecuencia de problemas de infertilidad, se trasladaron a Estados Unidos y contrataron respectivamente los servicios de una mujer, la madre gestante, para poder concebir a sus hijas. Tras la implantación de dos embriones, en el caso Mennesson la mujer gestó a dos gemelas, Valentina y Fiorella, mientras que en el caso Labassee nació una niña, Juliette Monique. Es importante destacar en relación con el fallo del TEDH, que en ambos casos el material genético paterno correspondía al marido de la pareja francesa. En definitiva, los tribunales de California, caso Mennesson, y de Minnesota, caso Labassee, declararon por sentencia judicial, que cada una de las parejas francesas eran los padres de las respectivas niñas con arreglo al Derecho de California y Minnesota, respectivamente ${ }^{72}$.

29. Los ciudadanos franceses instaron la inscripción de esta filiación en el Registro Civil francés. Tras varias vicisitudes y batallas judiciales y registrales, la Cour de Cassation francesa denegó la inscripción de la filiación de las niñas con arreglo al Derecho de Estados Unidos ${ }^{73}$. Ésta consideró que

\footnotetext{
${ }^{71}$ FD VIII SAP Islas Baleares núm. 207/2021 de 27 abril (JUR\2021\163294).

72 STEDH 26 junio 2014, Mennesson c. Francia, 65192/11 (JUR $2014 \backslash 176908)$ (ECLI:CE:ECHR:2014:0626J UD006519211), apartados 6-10; STEDH 26 junio 2014, Labassee c. Francia, 65941/11 (JUR\2014\176905) (ECLI:CE:ECH R:2014:0626JUD006594111), apartados 6-10.

${ }^{73}$ Se denegó la inscripción de las menores en el Registro Civil francés, mediante sentencia de fecha 6 de abril de 2011 de la Cour de Cassation francesa, a pesar de que uno de los padres comitentes había aportado sus gametos masculinos (A. QuiÑNES ESCÁMEZ, "Doble filiación paterna de gemelos nacidos en el extranjero mediante maternidad subrogada. En torno a la RDGRN de 18 de febrero de 2009", Indret, no 3, Editorial Universitat Pompeu Fabra, Barcelona, julio 2009, pp. 9-12; A. HeRnÁNDEZ
} 
la gestación por sustitución era un contrato nulo por infracción del orden público francés ${ }^{74}$. El Código Civil francés prohíbe la maternidad subrogada en los arts. 16-7 y 16-975.

Como consecuencia de la denegación de la inscripción registral y del reconocimiento de la filiación de las niñas, los padres comitentes decidieron recurrir tales pronunciamientos ante el TEDH. En ambos recursos los padres comitentes alegaron que dicha denegación vulneraba el art. 8 del CEDH (Convenio Europeo de Derechos Humanos), que recoge el derecho al respeto a la "vida privada y familiar" de las personas ${ }^{76}$.

30. Por consiguiente, se argumenta en el recurso que al no atribuirse la filiación a favor de los padres comitentes, se vulneraba el derecho al respeto a la vida privada y familiar de los menores, puesto que se les sitúa en una posición de incertidumbre jurídica: las niñas no podían tener la nacionalidad francesa y no podrían ser herederas de los padres comitentes ${ }^{77}$.

En relación con ambos asuntos son especialmente trancendentes las sentencias dictadas por el TEDH, así como el primer Dictamen realizado por el TEDH en materia de gestación por sustitución en relación con el caso Mennesson.

\section{Sentencias del TEDH de 26 de junio de 2014, asuntos Mennesson y Labassee}

31. Ambas resoluciones fueron dictadas por el TEDH en relación a los casos Mennesson contra Francia y Labassee contra Francia, ambas de fecha 26 de junio de 2014, así que serán examinadas conjuntamente por presentar características similares ${ }^{78}$. Por esta razón, el 12 de febrero de 2012, el TEDH, tras comunicar al gobierno francés la demanda presentada por las partes contra él, decidió que la instrucción de ambos casos sería realizada de manera simultánea ${ }^{79}$.

RoDRíGUEZ, "La determinación de la filiación de los nacidos en el extranjero mediante gestación por sustitución: ¿Hacia una nueva regulación en España?", Cuadernos de Derecho Transnacional (CDT), vol. 6, no 2, octubre 2014, pp. 169-173; A.-L. Calvo Caravaca/ J. Carrascosa González, "La gestación por sustitución y derecho internacional privado. Más allá del Tribunal Supremo y del Tribunal Europeo de Derechos Humanos", Cuadernos de Derecho Transnacional (CDT), vol. 7, $\mathrm{n}^{\circ} 2$, octubre 2015, pp. 94-95; A. AzNAR Domingo, "Regulación y análisis de la gestación por sustitución en España", Diario La Ley, Wolters Kluwer, no 9099, 14 diciembre 2017, p. 12; J. Carrascosa GonzÁlez, "Filiación natural”, en A.-L. Calvo Caravaca/ J. Carrascosa GonzÁlez (dirs.), Tratado de Derecho Internacional Privado, Tomo II, Tirant lo Blanch, Valencia, 2020, p. 1899).

${ }^{74}$ STEDH 26 junio 2014, Mennesson c. Francia, 65192/11 (JUR\2014\176908) (ECLI:CE:ECHR:2014:0626J UD006519211), apartado 82; STEDH 26 junio 2014, Labassee c. Francia, 65941/11 (JUR 2014\176905) (ECLI:CE:ECHR: 2014:0626JUD006594111), apartado 61.

${ }^{75} \mathrm{El}$ art. 16-7 del Código Civil francés indica "Toute convention portant sur la procréation ou la gestation pour le compte d'autrui est nulle", mientras que el art. 16-9 señala que la anterior norma es una norma imperativa, no disponible por las partes, y de observancia obligatoria en todos los casos, "disposition d'ordre public" (A.-L. Calvo Caravaca/ J. Carrascosa GonzÁLEZ, "La gestación por sustitución y derecho internacional privado. Más allá del Tribunal Supremo y del Tribunal Europeo de Derechos Humanos", Cuadernos de Derecho Transnacional (CDT), vol. 7, nº 2, octubre 2015, p. 94; J. CARrascosa GonZÁlez, "Filiación natural", en A.-L. Calvo Caravaca/ J. Carrascosa GonzÁlez (dirs.), Tratado de Derecho Internacional Privado, Tomo II, Tirant lo Blanch, Valencia, 2020, pp. 1899-1900).

${ }^{76}$ Art. 8 Convenio Europeo de Derecho Humanos (Instrumento de Ratificación del Convenio para la Protección de los Derechos Humanos y de las Libertades Fundamentales, hecho en Roma el 4 de noviembre de 1950, y enmendado por los Protocolos adicionales números 3 y 5, de 6 de mayo de 1963 y 20 de enero de 1966, respectivamente, (BOE núm. 243, 10 octubre 1979), en vigor para España desde el 4 de octubre de 1979).

77 A. Hernández Rodríguez, "La determinación de la filiación de los nacidos en el extranjero mediante gestación por sustitución: ¿Hacia una nueva regulación en España?”, Cuadernos de Derecho Transnacional (CDT), vol. 6, nº 2, octubre 2014, pp. 169-173; A.-L. Calvo CaravaCa/ J. CARrascosa GonzÁlez, "La gestación por sustitución y derecho internacional privado. Más allá del Tribunal Supremo y del Tribunal Europeo de Derechos Humanos", Cuadernos de Derecho Transnacional (CDT), vol. 7, n 2, octubre 2015, pp. 94-95; A. AzNAR Domingo, "Regulación y análisis de la gestación por sustitución en España", Diario La Ley, Wolters Kluwer, no 9099, 14 diciembre 2017, pp. 12-13; J. CARrascosa GonzÁlez, "Filiación natural”, en A.L. Calvo Caravaca/ J. Carrascosa González (dirs.), Tratado de Derecho Internacional Privado, Tomo II, Tirant lo Blanch, Valencia, 2020, p. 1895.

${ }^{78}$ STEDH26junio 2014, Mennessonc. Francia, 65192/11 (JUR\2014\176908)(ECLI:CE:ECHR:2014:0626JUD006519211); STEDH 26 junio 2014, Labassee c. Francia, 65941/11 (JUR 2014\176905) (ECLI:CE:ECHR:2014:0626JUD006594111).

${ }^{79}$ STEDH 26 junio 2014, Mennesson c. Francia, 65192/11 (JUR\2014\176908) (ECLI:CE:ECHR:2014:0626J 
En primer lugar, el TEDH señaló que cada Estado parte en el CEDH podía regular la gestación por sustitución como estimase conveniente ya sea, tanto en su vertiente negativa como en su vertiente positiva, esto es, o bien, permitiendo y regulando la maternidad subrogada o, en caso contrario, negando cualquier efecto sobre la filiación de los menores nacidos por esta vía. Existe una opción intermedia, que es prohibir el proceso, pero con una particularidad, reconociendo la filiación determinada conforme a la resolución judicial extranjera y otorgándole plenos efectos jurídicos ${ }^{80}$. En consecuencia, se podrá optar por cualquiera de estas tres opciones, pero siempre respetando el principio del "interés superior del menor" $"$.

\section{A) EI derecho al respeto a la "vida privada y familiar"}

32. La interpretación que viene haciendo el TEDH, en relación al derecho a la identidad personal recogido en el art. 8 del CEDH, puede implicar un derecho a la continuidad transfronteriza de los estatutos personales y las relaciones familiares creadas en el extranjero ${ }^{82}$. De hecho, el no reconocimiento de los estatutos familiares creados válida y efectivamente en el extranjero interfiere con el derecho a la vida privada y familiar.

Las condiciones exigidas por el art. 8 del CEDH para gozar de ese derecho son: a) Desde un punto de vista formal, que el vínculo familiar haya sido creado válida y legalmente antes de solicitar su reconocimiento; b) Desde un punto de vista sustancial, que la relación familiar se haya establecido como una realidad social, habiendo vivido el niño con el padre biológico y de intención desde que nació. Además, se deben tener en cuenta los intereses esenciales del niño, que deben ser una consideración primordial del Estado ${ }^{83}$.

33. En cuanto al derecho al respeto a la vida privada, el TEDH les dio la razón a los padres comitentes, pues se había vulnerado el art. 8 del CEDH y exigió que fueran considerados como "hijos" de los padres comitentes, aunque se hubiese demostrado que sólo uno de ellos fuese el padre biológico de las niñas. El respeto al derecho a la vida privada de los niños y las niñas que contempla ese artículo se encuentra relacionado con la determinación de la filiación de los menores. Si las menores no tienen establecida una filiación, éstas no tendrán nombre y apellidos, es decir no poseerán una identidad única, con lo cual el principio del derecho a la vida privada se estará vulnerando ${ }^{84}$.

En este sentido, la afectación al derecho al respeto a la vida privada se debe a la absoluta imposibilidad de que el ordenamiento jurídico francés reconozca cualquier vínculo de filiación entre los comitentes y el niño, no solamente por la denegación de la transcripción del acta de nacimiento extranjera; sino porque

UD006519211), apartado 3; STEDH 26 junio 2014, Labassee c. Francia, 65941/11 (JUR\2014\176905) (ECLI:CE:ECHR:20 14:0626JUD006594111), apartado 3.

${ }^{80}$ STEDH 26 junio 2014, Labassee c. Francia, 65941/11 (JUR\2014\176905) (ECLI:CE:ECHR:2014:0626JUD006594111), apartados 57-58.

${ }^{81}$ STEDH 26 junio 2014, Mennesson c. Francia, 65192/11 (JURl2014\176908) (ECLI:CE:ECHR:2014:0626JUD006519211), apartado 63; STEDH 26 junio 2014, Labassee c. Francia, 65941/11 (JUR\2014\176905) (ECLI:CE:ECHR:2014:0626J UD006594111), apartado 60. Vid. A. AzNAR Domingo, "Regulación y análisis de la gestación por sustitución en España", Diario La Ley, Wolters Kluwer, no 9099, 14 diciembre 2017, p. 13; J. Carrascosa GonzÁlez, "Filiación natural”, en A.-L. Calvo Caravaca/ J. Carrascosa GonzÁlez (dirs.), Tratado de Derecho Internacional Privado, Tomo II, Tirant lo Blanch, Valencia, 2020, p. 1896.

${ }^{82}$ F. Marongiu Buonaiuti, "La continuità internazionale delle situazioni giuridiche e la tutela dei diritti umani di natura sostanziale: strumenti e limiti”, Rivisteweb, núm. 1, 2016, pp. 49-88.

${ }^{83}$ STEDH Gran Sala 6 julio 2010, Neulinger and Shuruk v. Switzerland, 41615/17 (JUR\2010\227323), apartado 135.

${ }^{84}$ A. Hernández Rodríguez, "La determinación de la filiación de los nacidos en el extranjero mediante gestación por sustitución: ¿Hacia una nueva regulación en España?”, Cuadernos de Derecho Transnacional (CDT), vol. 6, nº 2, octubre 2014, pp. 169-173; A.-L. Calvo Caravaca/ J. Carrascosa GonzÁlez, "La gestación por sustitución y derecho internacional privado. Más allá del Tribunal Supremo y del Tribunal Europeo de Derechos Humanos", Cuadernos de Derecho Transnacional (CDT), vol. 7, n 2, octubre 2015, pp. 94-95; A. Aznar Domingo, "Regulación y análisis de la gestación por sustitución en España", Diario La Ley, Wolters Kluwer, no 9099, 14 diciembre 2017, pp. 12-13; J. CARrascosa GonzÁLez, "Filiación natural", en A.L. Calvo Caravaca/ J. Carrascosa González (dirs.), Tratado de Derecho Internacional Privado, Tomo II, Tirant lo Blanch, Valencia, 2020, pp. 1892-1893. 
la Cour de Cassation francesa impide el reconocimiento de la paternidad biológica paterna, así como la filiación derivada de la posesión de estado, o la filiación por adopción por parte de los padres comitentes, con lo cual los menores tampoco podrán adquirir la nacionalidad francesa, ni heredar en calidad de hijas, lo que implica una situación de incertidumbre jurídica incompatible con el art. 8 del $\mathrm{CEDH}^{85}$.

Sin embargo, el TEDH en dichas sentencias no señala cómo ha de realizarse dicho reconocimiento de la filiación de manera efectiva en el Estado francés, puesto que tal y como aclaró posteriormente, es cada Estado, el que tendrá que llevarlo a cabo de conformidad con sus propias normas ${ }^{86}$.

34. Por otro lado, en cuanto al derecho a la vida familiar, el TEDH consideró que, a pesar del no reconocimiento en Derecho francés de la filiación entre los menores y sus progenitores, no había habido vulneración de tal derecho, pues los menores se encontraban desde su nacimiento integrados en un núcleo familiar estable, por lo que habían constituido una familia en Francia ${ }^{87}$.

En virtud del art. 8 del CEDH, la familia formada en el Estado de origen tiene derecho a vivir como una familia en el Estado de destino. Cuando no se admite la filiación de un menor nacido tras una gestación por sustitución, legalmente determinada en otro Estado, puede ser que el menor no pueda vivir con sus padres, con lo que se infringe el derecho a la vida familiar. Si se comprueba que como consecuencia del no reconocimiento de la filiación, los menores y sus padres comitentes no han sido considerados una familia en el Estado de destino y no han sido protegidos como tales, porque los niños hayan sido separados de sus padres comitentes, por ejemplo, entonces sí se produce una vulneración del derecho a una vida familiar, y el Estado tendrá que ser condenado por el TEDH ${ }^{88}$.

\section{B) Concepción restrictiva y específica de “orden público internacional”}

35. Para la Cour de Cassation francesa los padres habían cometido un fraude de ley con su actuación, al trasladarse a un país donde la maternidad subrogada podía realizarse, aunque sabían que, en Francia, los menores nunca podrían ser inscritos como hijos de los padres comitentes. En definitiva, habían evitado la aplicación de la legislación francesa para conseguir el objetivo de la inscripción de la filiación de los menores a su favor. Sin embargo, el TEDH entendió que, el hecho de que los padres hubiesen actuado posiblemente en fraude de ley, no podía afectar a los menores nacidos por gestación por sustitución porque se estaría ante una clara infracción de la vida privada de los menores ${ }^{89}$.

Por lo tanto, en ambos casos, el TEDH situó la protección del principio del "interés superior del menor" por encima de cualquier otro principio, al considerarlo realmente "superior", al estar por encima del orden público internacional del país en cuestión, es decir, del orden público internacional francés ${ }^{90}$.

${ }^{85}$ STEDH 26 junio 2014, Mennesson c. Francia, 65192/11 (JUR\2014\176908) (ECLI:CE:ECHR:2014:0626J UD006519211), apartados 96 y 99; STEDH 26 junio 2014, Labassee c. Francia, 65941/11 (JUR\2014\176905) (ECLI:CE:EC HR:2014:0626JUD006594111), apartado 75 y 78.

${ }^{86}$ Conclusiones del Avis consultatif relatif à la reconnaissance en droit interne d'un lien de filiation entre un enfant né d'une gestation pour autrui pratiquée à l'étranger et la mère de'intention, de 10 de abril de 2019, solicitado por la Cour de Cassation francesa al TEDH (Demande ${ }^{\circ}$ P16-2018-001).

${ }^{87}$ STEDH 26 junio 2014, Mennesson c. Francia, 65192/11 (JUR\2014\176908) (ECLI:CE:ECHR:2014:0626JUD006519211) , apartado 93; STEDH 26 junio 2014, Labassee c. Francia, 65941/11 (JUR\2014\176905) (ECLI:CE:ECHR:2014:0626J UD006594111), apartado 72. Vid. A.-L. Calvo Caravaca/ J. Carrascosa GonzÁlez, "La gestación por sustitución y derecho internacional privado. Más allá del Tribunal Supremo y del Tribunal Europeo de Derechos Humanos”, Cuadernos de Derecho Transnacional (CDT), vol. 7, nº 2, octubre 2015, p. 95; J. CARrascosa GonZÁlez, "Filiación natural", en A.-L. Calvo CARAVACA/ J. Carrascosa GonzÁlez (dirs.), Tratado de Derecho Internacional Privado, Tomo II, Tirant lo Blanch, Valencia, 2020 , p. 1894.

${ }^{88}$ STEDH26junio 2014, Mennesson c. Francia, 65192/11 (JUR\2014\176908)(ECLI:CE:ECHR:2014:0626JUD006519211), apartados 87-94; STEDH 26 junio 2014, Labassee c. Francia, 65941/11 (JUR\2014\176905) (ECLI:CE:ECHR:2014:0626J UD006594111), apartados 66-73. Vid. J. Carrascosa GonzÁlez, "Filiación natural”, en A.-L. Calvo Caravaca/ J. Carrascosa GonzÁlez (dirs.), Tratado de Derecho Internacional Privado, Tomo II, Tirant lo Blanch, Valencia, 2020, pp. 1894-1895.

${ }^{89}$ A. Aznar Domingo, "Regulación y análisis de la gestación por sustitución en España", Diario La Ley, Wolters Kluwer, no 9099, 14 diciembre 2017, p. 13; J. Carrascosa GonzÁlez, "Filiación natural", en A.-L. Calvo Caravaca/ J. Carrascosa GonzÁlez (dirs.), Tratado de Derecho Internacional Privado, Tomo II, Tirant lo Blanch, Valencia, 2020, pp. 1894-1895.

${ }^{90}$ STEDH 26 junio 2014, Mennesson c. Francia, 65192/11 (JUR\2014\176908) (ECLI:CE:ECHR:2014:0626JUD006519211), 
36. En este sentido el TEDH es partidario de una concepción restrictiva y específica del orden público internacional: restrictiva en el sentido de que sólo se podrá denegar la inscripción de la filiación de los menores a favor de los padres comitentes si se prueba que el menor ha sido objeto de comercio, que la madre gestante fue engañada y prestó un consentimiento no informado, o que vendió sus servicios con ánimo de lucro, o que la mujer gestante fue obligada a prestar sus servicios por una situación de pobreza, entre otros; y específica, porque las circunstancias anteriores sólo pueden valorarse en el caso concreto, pues en toda intervención de orden público los datos del caso son relevantes ${ }^{91}$.

Se puede observar en ambos asuntos, cómo el TEDH interviene para establecer los límites al orden público internacional francés. En este sentido, el margen en la exclusividad estatal de delimitación del orden público estatal va desapareciendo progresivamente conforme el TEDH va resolviendo más y más casos específicos, en relación con diferentes materias. Puesto que, cuando el TEDH resuelve si un Estado ha vulnerado o no alguno de los derechos consagrados por el CEDH - que a su vez forma parte integrante de su orden público- la concreción del contenido del derecho humano en cuestión para este supuesto de gestación por sustitución, también determina el contenido del orden público de todos los Estados parte del $\mathrm{CEDH}^{92}$.

37. En definitiva, finalmente Francia fue condenada en los asuntos Mennesson y Labassee a reconocer la filiación de los menores nacidos por gestación por sustitución, así como a abonar la correspondiente indemnización por daños morales a cada una de las niñas, concretamente 5000 euros $^{93}$.

\section{Primer Dictamen del TEDH de 10 de abril de 2019}

38. El primer Dictamen del TEDH en materia de gestación por sustitución de 10 de abril de 2019, fue a raíz de la solicitud de la Cour de Cassation francesa como consecuencia de la sentencia Mennesson contra Francia ${ }^{94}$. En dicha sentencia, como no puede ser de otra manera, no se establece cómo ha de procederse para el reconocimiento de la filiación de las niñas nacidas mediante un contrato de gestación por sustitución en California.

Así pues, la Cour de Cassation francesa para dar efectivo cumplimiento a lo señalado por el TEDH, decidió, por resolución de 21 de septiembre de 2017, que no existía ningún obstáculo a la inscripción del acta de nacimiento de las niñas nacidas mediante un contrato de gestación por sustitución en el extranjero, en el que el padre de intención o padre comitente sea inscrito como padre de las menores, puesto que es el padre biológico. Sin embargo, considera imposible que la madre de intención o madre comitente pueda ser inscrita como madre de las menores. A la mujer del padre, es decir madre comitente, se le ofrece la posibilidad de adoptar a las menores, si se cumplen las condiciones legales y si la adop-

apartados 63 y 82; STEDH 26 junio 2014, Labassee c. Francia, 65941/11 (JUR 2014\176905) (ECLI:CE:ECHR:2014:0626J UD006594111), apartados 60-61.

${ }^{91}$ A. Hernández Rodríguez, "La determinación de la filiación de los nacidos en el extranjero mediante gestación por sustitución: ¿Hacia una nueva regulación en España?”, Cuadernos de Derecho Transnacional (CDT), vol. 6, nº 2, octubre 2014, pp. 169-173; A.-L. Calvo Caravaca/ J. Carrascosa González, "La gestación por sustitución y derecho internacional privado. Más allá del Tribunal Supremo y del Tribunal Europeo de Derechos Humanos", Cuadernos de Derecho Transnacional (CDT), vol. 7, n² 2, octubre 2015, pp. 94-95; J. Carrascosa GonzÁlez, "Filiación natural”, en A.-L. Calvo Caravaca/ J. Carrascosa GonzÁlez (dirs.), Tratado de Derecho Internacional Privado, Tomo II, Tirant lo Blanch, Valencia, 2020, pp. 1895-1896.

${ }^{2}$ S. Álvarez GonzÁlez, ¿Orden público europeo versus orden público internacional de cada Estado?, en N. BouZA I VIDAL/ C. García i Segura/ A.-J. Rodrigo Hernández, P. Pareja Alcaraz (coords.), La gobernanza del interés público global: XXV Jornadas de la Asociación Española de Profesores de Derecho Internacional y Relaciones Internacionales, Tecnos, Madrid, 2015, p. 158-159.

${ }^{93}$ STEDH 26 junio 2014, Mennesson c. Francia, 65192/11 (JUR।2014\176908) (ECLI:CE:ECHR:2014:0626JUD006519211), apartado 116; STEDH 26 junio 2014, Labassee c. Francia, 65941/11 (JUR\2014\176905) (ECLI:CE:ECHR:2014:0626J UD006594111), apartado 85. Vid. A. AzNAR Domingo, "Regulación y análisis de la gestación por sustitución en España”, Diario La Ley, Wolters Kluwer, n 9099, 14 diciembre 2017, p. 13.

${ }^{94}$ Avis consultatif relatif à la reconnaissance en droit interne d'un lien de filiation entre un enfant né d'une gestation pour autrui pratiquée à l'étranger et la mère de'intention, de 10 de abril de 2019, solicitado por la Cour de Cassation francesa al TEDH (Demande n ${ }^{\circ}$ P16-2018-001). 
ción es conforme al interés del menor, es decir que crea un vínculo de filiación, puesto que la adopción del hijo del cónyuge es más sencilla bajo el Derecho frances ${ }^{95}$.

Sin embargo, la madre comitente, presentó una demanda, en calidad de representante legal de las menores, contra la sentencia de la Cour d'appel de Paris de 18 de marzo de 2010, que había anulado la transcripción en los registros del estado civil francés de las actas de nacimiento americanas de las niñas ${ }^{96}$.

Por ello, en el marco de este procedimiento, la Cour de Cassation francesa planteó dos cuestiones al TEDH ${ }^{97}$ :

1. Se ha rechazado la transcripción en los registros del estado civil francés del acta de nacimiento de un niño nacido en el extranjero en el que se designa como madre legal o legítima a la madre de intención, mientras que sí es posible la transcripción del acta en el que se designa al padre de intención como padre legal o legítimo, al padre biológico del menor. En este contexto, ¿un Estado parte se excede en el margen de apreciación en cuanto a la interpretación del art. 8 del CEDH? Así pues, ¿la solución es diferente en función de si el menor es concebido o no con los gametos de la madre de intención?

2. En el caso de que la respuesta sea positiva a cualquiera de estas cuestiones, ¿la posibilidad para la madre de intención de adoptar al hijo de su cónyuge, que es el padre biológico, constituye un modo de establecimiento de la filiación, que respeta las exigencias del art. 8 del CEDH?

39. En este Dictamen, concluye el TEDH, respondiendo a las preguntas planteadas por la Cour de Cassation, que en este supuesto planteado, en el que la relación jurídica paterno-filial con el padre comitente ha sido reconocida en la legislación nacional francesa, el derecho del niño al respeto de su vida privada en el sentido del artículo 8 del $\mathrm{CEDH}$, exige que la legislación nacional prevea la posibilidad de reconocer una relación jurídica paterno-filial con la madre comitente, designada en el certificado de nacimiento legalmente establecido en el extranjero como "madre legítima" 98 .

Sin embargo, este derecho no exige que dicho reconocimiento adopte la forma de inscripción en el registro del estado civil de los datos de la partida de nacimiento legalmente establecida en el extranjero; pueden utilizarse otros medios, como la adopción del niño por la madre comitente, siempre que el procedimiento establecido por la legislación nacional garantice que pueda ser aplicado con prontitud y eficacia, de conformidad con el interés superior del niño ${ }^{99}$.

40. El TEDH tiene en cuenta dos factores para llegar a las anteriores conclusiones: el primero de ellos es la preservación del superior interés del menor, que considera primordial; y el segundo se refiere al alcance del margen de discrecionalidad de que disponen los Estados contratantes de acuerdo con el art. 8 del $\mathrm{CEDH}^{100}$.

Recuerda el TEDH que la falta de reconocimiento de una relación jurídica entre un niño nacido mediante un contrato de gestación por sustitución realizado en el extranjero y la madre comitente, tiene un impacto negativo en varios aspectos del derecho del menor al respeto de su vida privada, pues coloca al niño en una situación de inseguridad jurídica con respecto a su identidad en la sociedad y así lo observó el Tribunal en sus sentencias Mennesson y Labasse. Los riesgos concretos para el menor consistirían en que se le niegue el acceso a la nacionalidad de la madre comitente que garantiza la filiación; que se complique la permanencia del menor en el país de residencia de la madre comitente -aunque este riesgo no exista en el caso planteado porque el padre de intención que es el padre biológico tenga la naciona-

\footnotetext{
${ }^{95}$ Avis consultatif relatif à la reconnaissance en droit interne d'un lien de filiation entre un enfant né d'une gestation pour autrui pratiquée à l'étranger et la mère de'intention, de 10 de abril de 2019, solicitado por la Cour de Cassation francesa al TEDH (Demande $\left.\mathrm{n}^{\circ} \mathrm{P} 16-2018-001\right)$, apartado 14.

${ }^{96} \mathrm{Idem}$, apartado 16.

${ }^{97} \mathrm{Idem}$, apartado 10.

${ }^{98}$ Idem, apartado 46.

${ }^{99}$ Idem, apartado 55.

${ }^{100}$ Idem, apartado 37.
} 
lidad francesa-; que los derechos sucesorios se vean disminuidos; que la relación con su madre pueda correr riesgo si los padres comitentes se separan o si el padre comitente fallece; y que el menor carezca de protección en el caso de que la madre comitente lo rechace o deje de ocuparse de él ${ }^{101}$.

Por estas razones y aunque el TEDH es consciente de los riesgos de abuso que implican los contratos de gestación por sutitución y los problemas que genera la posibilidad de conocer el origen de la persona, termina concluyendo que el interés superior del niño también supone identificar jurídicamente a las personas responsables de su educación, de satisfacer sus necesidades y garantizar su bienestar, así como asegurarse de que el menor crezca y se desarrolle en un entorno estable ${ }^{102}$.

Por lo tanto, el Tribunal considera que la imposibilidad general y absoluta de obtener el reconocimiento del vínculo entre un niño nacido por medio de un contrato de maternidad subrogada celebrado en el extranjero y la madre comitente es incompatible con el interés superior del niño, que exige, por lo menos, que cada situación sea examinada teniendo en cuenta las circunstancias particulares de cada caso ${ }^{103}$.

41. En relación con el segundo factor, la discrecionalidad de los Estados, el Tribunal en su Dictamen y tras constatar que no existe consenso en Europa sobre la maternidad subrogada, señala que tanto cuando entra en juego una faceta particularmente importante de la identidad de una persona, como cuando se trata de la filiación, el margen permitido al Estado es normalmente limitado, por lo que es conveniente reducir el margen de apreciación del que dispone el Estado demandante ${ }^{104}$.

Pues bien, cuando se trata del reconocimiento del vínculo de filiación de los niños nacidos mediante gestación por sustitución y los padres de intención, sobrepasa incluso la cuestión de la identidad de los menores. Existen incluso otros aspectos de su vida privada que se ven afectados como son el entorno en el que ellos viven y se desarrollan, así como las personas que son responsables de satisfacer sus necesidades y de asegurar su bienestar. Esto respalda la observación del TEDH en lo que respecta a la reducción del margen de apreciación ${ }^{105}$.

En consecuencia, teniendo en cuenta el principio de interés superior del menor y la reducción del margen de apreciación, el derecho al respeto a la vida privada, de conformidad con el art. 8 del CEDH, debe interpretrase en el sentido de que la legislación nacional ofrezca en el supuesto planteado, la posibilidad de reconocer una relación jurídica paterno-filial con la madre comitente, que ha sido designada en el certificado de nacimiento legalmente establecido en el extranjero como "madre legítima"106.

42. Ahora bien, una cuestión distinta es el margen de apreciación del que dispone cada Estado en lo relativo a la elección de los medios que permitan reconocer la relación jurídica entre el menor y la madre comitente. El TEDH afirma que existe un consenso europeo en cuanto al establecimiento o el reconocimiento del vínculo de filiación entre el menor y el padre de intención, pero las modalidades en que se realiza varían de Estado a Estado. Por lo tanto, la elección de los medios mediante los cuales sea posible el reconocimiento de dicho vínculo entran dentro del margen de apreciación de los Estados $^{107}$.

El TEDH señala que el respeto al principio de superior interés del niño -que se evaluará en concreto y no en abstracto-, implica que el reconocimiento de esa relación, legalmente establecida en el extranjero, sea posible como máximo cuando tal relación se haya convertido en una realidad práctica, lo cual debe ser analizado por la autoridad de cada Estado ${ }^{108}$. El interés superior del niño no puede interpretarse en el sentido de que el reconocimiento de la relación jurídica paterno-filial entre el niño y la madre comitente, implique obligatoriamente la transcripción del certificado de nacimiento extranjero

\footnotetext{
${ }^{101}$ Idem, apartado 40.

${ }^{102}$ Idem, apartados 41 y 42.

${ }^{103} \mathrm{Idem}$, apartado 42.

${ }^{104}$ Idem, apartados 43 y 44.

${ }^{105}$ Idem, apartado 45.

${ }^{106}$ Idem, apartado 46.

${ }^{107} \mathrm{Idem}$, apartado 51.

${ }^{108}$ Idem, apartado 52.
} 
en el que se designa a la madre comitente como "madre legítima". En este sentido, dependiendo de las circunstancias de cada caso, otros medios también pueden servir a esos intereses de manera adecuada, incluida la adopción ${ }^{109}$.

No obstante, el TEDH matiza que, de acuerdo con la evaluación de las circunstancias de cada caso, tiene que existir un mecanismo eficaz que permita reconocer la relación entre el niño y la madre comitente, lo antes posible y en todo caso cuando dicha relación se haya convertido en una realidad práctica. Por lo que la adopción puede cumplir este requisito siempre que las condiciones que la regulen sean adecuadas y el procedimiento permita tomar rápidamente una decisión, de modo que el niño no se encuentre durante un largo periodo en una situación de inseguridad jurídica ${ }^{110}$.

43. En definitiva, para el TEDH lo fundamental es proteger el interés superior del menor, concretado en este supuesto en el respeto de su vida privada y en la necesidad de reconocimiento del vínculo de filiación entre la madre comitente y el hijo. Para conseguir este objetivo y siempre atendiendo a las circunstancias de cada supuesto, no son tan importantes los instrumentos normativos para conseguir dicho objetivo, siempre que sean eficaces y ágiles, sin que se tenga que excluir necesariamente la inscripción de la partida de nacimiento establecida en el extranjero conforme a la legislación del país de que se trate.

Por un lado, la Cour de Cassation indica que la ley francesa facilita la adopción del hijo del cónyuge, de forma que esta puede tratarse de una adopción simple o plena, como sucede en España ${ }^{111}$. Sin embargo, aunque el gobierno francés aclara que entre el 5 de julio de 2017 y el 2 de mayo de 2018, prácticamente la totalidad de las demandas de adopción entre esposos en relación con niños nacidos en el extranjero por gestación por sustitución, el TEDH destaca que este procedimiento sólo es posible para aquellos padres de intención que estén casados. Por lo que se mantiene la incertidumbre en lo que respecta a las modalidades de adopción por parte del cónyuge en este asunto, pues se exige por ejemplo la necesidad del consentimiento previo de la madre gestante ${ }^{112}$. Aunque el TEDH señala que esta no es una cuestión sobre la que deba é mismo pronunciarse, sino que será el juez nacional quien tendrá que hacerlo teniendo en cuenta la situación de inseguridad en la que se encuentran los menores, mientras el procedimiento de adopción esté pendiente ${ }^{113}$. No obstante, tuvo que manifestarse posteriormene, en su reciente sentencia de 16 de julio de 2020, asunto D. c Francia, en la que señaló que la adopción plena genera los mismos vínculos familiares que la filiación natural y que los procedimientos de adopción plena tienen una duración de alrededor cuatro meses ${ }^{114}$.

No obstante, teniendo en cuenta las circunstancias del caso, el juez consideró que, después de quince años de proceso judicial, el interés superior del menor requería un reconocimiento inmediato de

\footnotetext{
${ }^{109}$ Idem, apartado 53.

${ }^{110}$ Idem, apartado 54.

${ }^{111}$ Idem, apartado 56.

${ }^{112}$ Idem, apartado 57.
}

${ }^{113}$ Idem, apartado 58. El TEDH es consciente de la complejidad de las cuestiones relativas a la gestación por sustitución. En este sentido, la conferencia de la Haya de derecho internacional privado ha emprendido diversos trabajos destinados a proponer una convención internacional que permita responder a estas cuestiones sobre la base de los principios aceptados por los Estados que se adhirieron a este instrumento internacional (Avis consultatif relatif à la reconnaissance en droit interne d'un lien de filiation entre un enfant né d'une gestation pour autrui pratiquée à l'étranger et la mère de'intention, de 10 de abril de 2019 , solicitado por la Cour de Cassation francesa al TEDH (Demande no P16-2018-001), apartado 59).

${ }^{114}$ STEDH 16 julio 2020, 11288/18, D c Francia, (JUR\2020\214195) (ECLI:CE:ECHR:2020:0716JUD001128818), apartados 66 y 67 . En esta asunto, se desestimó la demanda de inscripción del acta de nacimiento de un niño nacido en el extranjero en el que se designaba como madre a la madre genética o biológica, pero que no había sido la madre gestante. La adopción fue el medio ofrecido para el reconocimiento del vínculo de filiación entre la madre de intención, que también era la biológica y el menor nacido mediante un contrato de gestación por sustitución; pues el padre de intención que también era el padre biológico, sí que fue reconocido como tal. Sin embargo, esta opción de la adopción para la madre comitente fue rechazada por los padres comitentes que solicitaron la inscripción de la certificación de nacimiento extranjera, alegando vulneración del art. 8 del TEDH. Pero, el TEDH determinó que no existía tal vulneración, puesto que los procedimientos de adopción plena tienen de una duración de alrededor de cuatro meses en Francia, por lo que había una celeridad razonable en los procedimientos de adopción plena en dicho Estado. 
la relación materno-filial, sin imponer a la futura madre tener que atravesar por todo el procedimiento de adopción ${ }^{115}$.

44. Por lo tanto, tras este análisis, podría concluirse que el TEDH apuesta por una concepción restrictiva y específica del orden público internacional, de manera que viene a limitar la aplicación del orden público y sólo debe activarse en supuestos concretos en los que exista un peligro grave real, tanto para la madre gestante como para el menor. En definitiva, se está limitando el concepto de orden público de cada Estado, cuando se trata del reconocimiento del vínculo de filiación entre los padres comitentes y el menor que ha nacido mediante un contrato de gestación por sustitución en el extranjero.

Sin embargo, la invocación de la cláusula de orden público - con el fin de denegar la transcripción del certificado de nacimiento extranjero- sería legítima, a la luz del margen de apreciación del Estado, siempre que, en todo caso, la adopción u otros procedimientos disponibles constituyan un medio eficaz que permita reconocer la relación paterno-filial, que sea rápido y que permita una evaluación por los juezes del interés superior del niño a la luz de las circunstancias del caso.

En definitiva, como se ha señalado en el epígrafe segundo, existiría un orden público europeo integrado no sólo por los principios recogidos en el Convenio Europeo de Derechos Humanos, como son el derecho al "respeto a la vida privada" (art. 8), sino por los principios contenidos en la Convención de los Derechos del Niño, concretamente el principio del "interés superior del menor" (art. 3).

\section{Orden público internacional en Italia en materia de gestación por sustitución}

45. El orden público internacional italiano es el motivo que se ha venido utilizando por los tribunales italianos para no proceder al reconocimiento de la filiación a favor de los padres comitentes de menores nacidos en el extranjero mediante contratos de gestación por sustitución.

46. Sin embargo, como consecuencia del primer Dictamen del TEDH en materia de gestación por sustitución de 10 de abril de 2019, ha provocado que, en abril del 2020, se planteara ante el Tribunal Constitucional italiano la cuestión de si la interpretación que se ha venido haciendo por parte de los tribunales italianos - de no reconocimiento de la filiación a favor de los padres comitentes porque atenta contra el orden público italiano- es coherente con la Constitución italiana ${ }^{116}$.

No deja de sorprender que en España no se haya planteado una cuestión similar que permita dar una respuesta uniforme a los casos de gestación de sustitución, de forma que en función de la valoración del tribunal que conoce del asunto se está dando validez o no a los contratos de gestación por sustitución realizados en el extranjero. Aunque como se ha visto en el epígrafe correspondiente, se puede afirmar que, de los casos analizados, las consecuencias jurídicas diferentes derivan de supuestos de hecho distintos.

47. Se estudiará, por tanto, en qué supuestos de gestación por sustitución se activa el orden público internacional italiano y cómo se conjuga dicho orden público internacional con los principios internacionales del CEDH, es decir, con el orden público europeo.

${ }^{115}$ L. Acconciamessa, "The Italian Constitutional Court Asked to Rule on Surrogacy Arrangements and Public Police", EAPIL (The European Association of Private International Law), 28 septiembre 2020, disponible en https://eapil.org/2020/09/28/ the-italian-constitutional-court-asked-to-rule-on-surrogacy-arrangements-and-public-policy/?utm_source=mailpoet\&utm medium=email\&utm_campaign=new-contents-on-the-eapil-blog_2 (consultado el 1 de abril de 2021).

${ }^{116}$ L. Acconciamessa, "The Italian Constitutional Court Asked to Rule on Surrogacy Arrangements and Public Police", EAPIL (The European Association of Private International Law), 28 septiembre 2020, disponible en https:/eapil.org/2020/09/28/ the-italian-constitutional-court-asked-to-rule-on-surrogacy-arrangements-and-public-policy/?utm_source=mailpoet\&utm _ medium=email\&utm_campaign=new-contents-on-the-eapil-blog_2 (consultado el 1 de abril de 2021). 


\section{Orden público internacional italiano}

48. El caso objeto de análisis es el de una pareja de italianos del mismo sexo que se casaron en Canadá. Dicho matrimonio fue reconocido en Italia como una pareja registrada, de acuerdo con el art. 32-bis del Estatuto italiano de Derecho internacional privado ${ }^{117}$. Posteriormente tuvieron un hijo en Canadá mediante un contrato de gestación por sustitución, donde estos contratos son válidos siempre que la madre gestante actúe de forma libre y altruista.

Aunque, el certificado de nacimiento del niño fue reconocido y registrado en Italia tras una decisión del Secretario de Verona, el certificado simplemente establecía que uno de los cónyuges tenía un vínculo biológico con el menor. Por esta razón, la pareja recurrió ante los tribunales canadientes para que se procediera a la rectificación del certificado de nacimiento del niño, pues querían que tanto el padre biológico como el padre comitente no biológico fueran reconocidos como padres del niño. Tras conseguir dicha rectificación en el certificado de nacimiento, solicitaron que dicho cambio fuera reconocido en Italia, pero su solicitud fue desestimada porque el orden público internacional italiano no permitía dicho reconocimiento ${ }^{118}$.

49. Para entender cuándo los tribunales italianos aplican el orden público internacional, se analizarán los aspectos, que, en materia de gestación por sustitución, tienen una incidencia directa sobre la activación o no del orden público internacional y que no son otros que el principio del "interés superior del menor" y el margen de apreciación de los Estados.

\section{A) El principio de "interés superior del menor"}

50. El Tribunal Supremo italiano ya había señalado en sentencias anteriores que el orden público incluye tanto los principios fundamentales de la Constitución italiana, como los recogidos en los instrumentos internacionales de Derechos Humanos. Así pues, el interés superior del menor y el derecho a su identidad social y personal formarían parte de los principios del orden público italiano. Por esos motivos, la Sala Primera señaló en una sentencia en 2016 que no podía recurrir a la defensa del orden público para impedir el reconocimiento de un certificado de nacimiento extranjero que acreditaba el parentesco familiar entre un niño y sus dos madres: la madre gestante y la que había donado el óvulo ${ }^{119}$.

Según este criterio, la simple incompatibilidad entre sentencias o actos públicos extranjeros y disposiciones imperativas internas no es suficiente para la activación del orden público italiano. Este es el mismo enfoque que ha seguido el Tribunal de Apelación de Venecia en el caso que se ha planteado al principio y que en la actualidad está pendiente ante el Tribunal Constitucional italiano. En particular, el Tribunal de Apelación sostuvo que el hecho de que la legislación italiana no prevea el matrimonio entre personas del mismo sexo y la atribución a una pareja del mismo sexo, de la condición de paternidad de un hijo nacido mediante técnicas de reproducción asistida, no supone que esto atente contra el orden público internacional italiano ${ }^{120}$.

Sin embargo, el Fiscal del Estado no estaba de acuerdo con la sentencia del Tribunal de Apelación del 2018 y solicitó que el Tribunal Supremo revisara la sentencia. Argumentó que el reconocimiento de la sentencia canadiense supondría una clara violación de la legislación italiana sobre filiación y

${ }^{117}$ Art. 32-bis Riforma del sistema italiano di diritto internazionale privato, Legge 31 maggio 1995, núm. 218 (GU núm. 128 del 03-06-1995 - Suppl. Ordinario n. 68), disponible en línea en https://www.normattiva.it/uri-res/N2Ls?urn:nir:stato:leg ge:1995;218 (consultado el 20 de junio de 2021).

${ }^{118}$ L. Acconciamessa, "The Italian Constitutional Court Asked to Rule on Surrogacy Arrangements and Public Police", EAPIL (The European Association of Private International Law), 28 septiembre 2020, disponible en https://eapil.org/2020/09/28/ the-italian-constitutional-court-asked-to-rule-on-surrogacy-arrangements-and-public-policy/?utm_source=mailpoet\&utm_ medium=email\&utm_campaign=new-contents-on-the-eapil-blog_2 (consultado el 1 de abril de 2021).

${ }^{119} \mathrm{Idem}$.

${ }^{120} \mathrm{Vid}$. Ordinanza depositata il 16 luglio 2018, disponible en línea en http://www.articolo29.it/wp-content/uploads/ 2018/07/20180716-0628-Ordinanza-accoglimento-Corte-appello-Venezia_oscurata.pdf (consultado el 25 de junio de 2021). 
técnicas de reproducción asistida médicamente y, por lo tanto, contraria al orden público italiano. Por lo tanto, el Fiscal del Estado invocó una concepción diferente del orden público de la que venía adoptando el Tribunal Supremo.

El punto de vista de las Joint Chambers es que que el reconocimiento del vínculo de filiación entre el niño nacido en régimen de gestación subrogada y el padre comitente, mediante el registro del certificado de nacimiento-, se justifica porque es el padre biológico. Ahora bien, el registro de la parte del certificado que designa como progenitor al padre comitente, que no es biológico, ni genético, estaría en contradicción con la prohibición italiana penal relativa a los contratos de gestación por sustitución ${ }^{121}$. Estas consideran que, al fin y al cabo, dicha regulación implementa los principios constitucionales relativos a la protección de la dignidad de la mujer y, por lo tanto, recoge un principio de orden público.

Las Joint Chambers, con el fin de garantizar el interés superior del menor, ofrece la posibilidad al padre comitente, que no es padre biológico, de que proceda a la adopción "en casos particulares" 122 . En su opinión, esta solución se encontraría en la línea de la doctrina del margen de apreciación del TEDH. En particular, se consideró que Italia ya había cumplido las normas del CEDH al reconocer plenamente la relación del niño con el padre biológico. Ahora bien, en ausencia de un vínculo biológico con el otro progenitor, las autoridades estatales mantendrían un amplio margen de apreciación al elegir el mecanismo apropiado para asegurar el establecimiento de una relación jurídica comparable, pero no idéntica, a la filiación natural ${ }^{123}$.

\section{B) EI margen de apreciación de los Estados}

51. Como ya se ha señalado en el epígrafe correspondiente, hasta el 2019, la interpretación del TEDH, asuntos Meneesson y Labassee, en relación al derecho a la "vida privada y familiar" (art. 8 $\mathrm{CEDH})$ es que para que se respete este derecho, se tienen que tener en cuenta dos aspectos: el interés superior del menor y el margen de discrecionalidad de los Estados.

En relación con el margen de apreciación de los Estados, si la injerencia se realiza de conformidad con la ley, persigue un fin legítimo y es "necesaria en una sociedad democrática" para lograrlo, puede definirse como legítima. Dicho derecho podría verse limitado mediante la aplicación de la cláusula de orden público. Los Estados disfrutan de un margen de apreciación para conseguir un equilibrio justo entre los intereses de los Estados y los derechos de las personas, que, se ha venido restringiendo progresivamente por el TEDH ${ }^{124}$.

52. En lo que respecta a margen de discrecionalidad de los Estados, es de especial interés el amplio margen de apreciación que adoptó el Estado italiano en el asunto Paradiso y Campanelli ${ }^{125}$.

\footnotetext{
${ }^{121}$ Art. 12.6 Estatuto italiano sobre la procreación asistida médicamente. Vid. Norme in materia di procreazione medicalmente assistita, Legge 19 febbraio 2004, núm. 40 (GU núm. 45 del 24-02-2004), disponible en línea en ttps://www.normattiva.it/urires/N2Ls?urn:nir:stato:legge:2004-02-19;40!vig= (consultado el 20 de junio de 2021).

${ }^{122}$ Art. 44.1 Estatuto Adopción italiana. Vid. Diritto del minore ad una familia, Legge 4 maggio 1983, núm. 184 (GU n.133 del 17-05-1983 - Suppl. Ordinario), disponible en línea en https:/www.normattiva.it/uri-res/N2Ls?urn:nir:stato:legge:198305-04;184!vig (consultado el 25 de junio de 2021). Es una especie de cláusula de último recurso que permite reconocer el vínculo afectivo entre el niño y el padre comitente no biológico, cuando éste sea también cónyuge del progenitor biológico o, en todo caso, siempre que la relación sea ya una realidad.

${ }^{123}$ L. Acconciamessa, "The Italian Constitutional Court Asked to Rule on Surrogacy Arrangements and Public Police", EAPIL (The European Association of Private International Law), 28 septiembre 2020, disponible en https://eapil.org/2020/09/28/ the-italian-constitutional-court-asked-to-rule-on-surrogacy-arrangements-and-public-policy/?utm_source=mailpoet\&utm medium=email\&utm_campaign=new-contents-on-the-eapil-blog_2 (consultado el 1 de abril de 2021).

${ }^{124}$ L. Acconciamessa, "The Italian Constitutional Court Asked to Rule on Surrogacy Arrangements and Public Police", EAPIL (The European Association of Private International Law), 28 septiembre 2020, disponible en https://eapil.org/2020/09/28/ the-italian-constitutional-court-asked-to-rule-on-surrogacy-arrangements-and-public-policy/?utm_source=mailpoet\&utm medium=email\&utm_campaign=new-contents-on-the-eapil-blog_2 (consultado el 1 de abril de 2021).

${ }^{125}$ STEDH 27 enero 2015, 25358/12, Paradiso y Campanelli c. Italia (ECLI:CE:ECHR:2015:0127JUD002535812); STEDH Gran Sala 24 enero 2017, 25358/12, Paradiso Campanelli (ECLI:CE:ECHR:2017:0124JUD002535812).
} 
La sentencia del TEDH de 24 de enero de 2017 daba por concluido el asunto Paradiso y Campanelli contra Italia, en el que las autoridades italianas declararon en situación de desamparo a un menor que había pasado sus primeros ocho meses de vida con los padres comitentes, dos cónyuges italianos que habían accedido a la gestación por sustitución con gametos donados en Rusia. La Gran Sala se apartó así de la interpretación realizada por la Sección $2^{\mathrm{a}}$ y consideró que la actuación de las autoridades italianas no vulneraba el art. 8 del CEDH. Así pues, no existía interferencia en la vida familiar de los comitentes, mientras que la injerencia en su vida privada se encontraba justificada ${ }^{126}$.

53. En la primera sentencia del año 2015 , de la Sección $2^{\mathrm{a}}$, el TEDH consideró contrario al art. 8 del Convenio la decisión de las autoridades italianas de alejar al niño de los padres comitentes y ponerle bajo la tutela de una institución, suprimiendo así toda posibilidad de contacto con dichos comitentes. El TEDH que la convivencia del niño durante más de seis meses con los comitentes implicaba que los tres habían constituido un núcleo familiar "de facto". Añade el Tribunal que "el alejamiento del niño del contexto familiar es una medida extrema a la que no se debería haber recurrido mas que como último recurso. Para que una medida de este tipo esté justificada, debe responder al fin de proteger al niño expuesto a un peligro inmediato para él", concluyendo que en este caso las medidas adoptadas por las autoridades italianas no respetaron el equilibrio justo que debía regir los intereses en juego ${ }^{127}$.

La activación del orden público debe ser razonada y proporcionada y debe respetar los derechos recogidos en el $\mathrm{CEDH}^{128}$. El TEDH afirmó en dicha sentencia que no se puede recurrir a la defensa de orden público como una especie de "carta en blanco" para cualquier medida, ya que el Estado tiene que respetar el interés superior del niño con independencia de la naturaleza del vínculo parental, genético o de otro tipo ${ }^{129}$.

54. Sin embargo, posteriormente, fue admitida a trámite la petición de los padres comitentes, en relación a la violación del art. 8, apartado primero, del CEDH, por considerar que los padres comitentes y el menor habían formado una familia de facto y que, además, los padres comitentes habían formado un vínculo emocional con el menor, según el informe psicológico ${ }^{130}$.

El TEDH reconoció que la retirada del menor a los padres comitentes fue realizada de acuerdo con la ley y que estos no tenían capacidad de representación, tal y como señaló en Gobierno italiano ${ }^{131}$. Sin embargo, consideró que el Gobierno italiano no había tenido en cuenta ni los derechos, ni el interés superior del menor, sin que por ello, estuviesen obligados a devolver el menor a los padres comitentes, porque el niño ya había desarrollado vínculos familiares con la familia de acogida ${ }^{132}$. De hecho, el TEDH también rechazó las observaciones del Gobierno italiano en contra de la demanda realizada por el matrimonio Paradiso-Campanelli ${ }^{133}$.

${ }^{126}$ E. Farnós-Amorós, "Paradiso y Campanelli c. Italia (II): los casos difíciles crean mal derecho (I)", Revista de Bioética y Derecho, núm, 20, 2017, disponible en línea en https://scielo.isciii.es/scielo.php?script=sci_arttext\&pid=S1886 -58872017000200017 (consultado el 25 de junio de 2021).

${ }^{127}$ STEDH 27 enero 2015, 25358/12, Paradiso y Campanelli c. Italia (ECLI:CE:ECHR:2015:0127JUD002535812).

128 J. Carrascosa González, "Filiación natural", en A.-L. Calvo Caravaca/ J. Carrascosa González (dirs.), Tratado de Derecho Internacional Privado, Tomo II, Tirant lo Blanch, Valencia, 2020, p. 1895.

${ }^{129}$ STEDH 27 enero 2015, 25358/12, Paradiso y Campanelli c. Italia (ECLI:CE:ECHR:2015:0127JUD002535812), apartado 80 .

${ }^{130}$ FH 34 STEDH Gran Sala 24 enero 2017, 25358/12, Paradiso Campanelli (ECLI:CE:ECHR:2017:0124JUD002535812). Vid. A.-M. Ruiz Martín, "El caso Campanelli y Paradiso ante el Tribunal Europeo de Derechos Humanos: El concepto de familia de facto y su aportación al debate de la gestación por sustitución”, Cuadernos de Derecho Transnacional (CDT), vol. 11, n 2 , octubre 2019, p. 782.

${ }^{131}$ FD 87 y ss. STEDH Gran Sala 24 enero 2017, 25358/12, Paradiso Campanelli (ECLI:CE:ECHR:2017:0124JUD00253 5812).

${ }^{132}$ STEDH Gran Sala 24 enero 2017, 25358/12, Paradiso Campanelli (ECLI:CE:ECHR:2017:0124JUD002535812), apartados 206, 210 y 213.

${ }^{133}$ A.-M. Ruiz Martín, "El caso Campanelli y Paradiso ante el Tribunal Europeo de Derechos Humanos: El concepto de familia de facto y su aportación al debate de la gestación por sustitución”, Cuadernos de Derecho Transnacional (CDT), vol. $11, \mathrm{n}^{\mathrm{o}} 2$, octubre 2019, p. 783 . 
Por lo tanto, sólo en caso de existir un peligro para el menor, un peligro grave real, es cuando se justifica la injerencia estatal con el fin de tutelar sus derechos fundamentales ${ }^{134}$. En principio, le corresponde a los progenitores o tutores velar por tales derechos, y sólo en caso de no hacerlo, entonces será el Estado el que debe intervenir, pero en casos de urgencia y necesidad siempre, según el apartado segundo del art. 8 del $\mathrm{CEDH}^{135}$.

55. En el asunto Paradiso y Campanelli, el hecho que tampoco existiese vínculo biológico con el menor, tal y como se suele exigir en las legislaciones de los Estados que permiten la gestación por sustitución para poder considerar que se ha creado un vínculo de filiación y con ello una "familia de facto", no fue el único aspecto que valoró el TEDH para entender que el Gobierno italiano había injerido en su vida privada y familiar de forma acertada ${ }^{136}$. En realidad, el aspecto fundamental para valorar que la separación al menor de los padres comitentes, no constituía una medida del gobierno italiano desproporcionada para el interés superior del menor, fue la actuación fraudulenta del matrimonio ParadisoCampanelli ${ }^{137}$. En este sentido, el TEDH consideró que no hubo injerencia en la vida familiar, porque no formaban una familia ${ }^{138}$.

Pero no sucedió lo mismo en cuanto a su derecho fundamental de tener una vida privada. Como el menor no fue considerado parte demandante en el proceso, porque no fue reconocido como hijo legítimo, pues únicamente se pudo tutelar en este caso, el derecho a tener una vida privada de los comitentes en su interacción con el menor. De forma que se diferenciaron dos derechos fundamentales pero relacionados en el art. 8 en el mismo nivel de protección: vida privada y familiar ${ }^{139}$. Así pues, dicho precepto, no viene a proteger el derecho o deseo a ser padres, sino el derecho a que cuando una familia se ha constituido de forma válida sea respetada por los Estados, incluyendo con ello la vida privada que se establece con el desarrollo del vínculo familiar ${ }^{140}$. Por esa razón, el TEDH consideró que la injerencia del Gobierno italiano en su vida privada estaba justificada.

\section{Orden público internacional vs. principios internacionales del CEDH}

56. Después del Primer Dictamen del TEDH de 10 de abril de 2019, en relación con el asunto Mennesson, el Tribunal Supremo procedió a delimitar el alcance del orden público italiano.

Para el Tribunal Supremo la interpretación del orden público que habían venido haciendo las Joint Chambers no era correcta, porque: por un lado, se había hecho prevalecer dicho orden público sobre el interés superior del menor sin una evaluación adecuada, es decir, caso por caso; y por otro lado, bajo el sistema legal italiano, la "adopción en casos particulares" no puede ser calificado como un mecanismo alternativo eficaz, que venga a sustituir a la no inscripción del vínculo de filiación tal y como aparece en la certificación registral extranjera ${ }^{141}$.

\footnotetext{
${ }^{134}$ A.-M. Ruiz Martín, "El caso Campanelli y Paradiso ante el Tribunal Europeo de Derechos Humanos: El concepto de familia de facto y su aportación al debate de la gestación por sustitución”, Cuadernos de Derecho Transnacional (CDT), vol. $11, \mathrm{n}^{\circ} 2$, octubre 2019 , p. 787.

${ }^{135}$ FH 63 STEDH Gran Sala 24 enero 2017, 25358/12, Paradiso Campanelli (ECLI:CE:ECHR:2017:0124JUD002535812).

${ }^{136}$ STEDH Gran Sala 24 enero 2017, 25358/12, Paradiso Campanelli (ECLI:CE:ECHR:2017:0124JUD002535812), apartado 149.

${ }^{137}$ STEDH Gran Sala 24 enero 2017, 25358/12, Paradiso Campanelli (ECLI:CE:ECHR:2017:0124JUD002535812), apartados 204 y 215.

${ }^{138}$ A.-M. Ruiz Martín, "El caso Campanelli y Paradiso ante el Tribunal Europeo de Derechos Humanos: El concepto de familia de facto y su aportación al debate de la gestación por sustitución”, Cuadernos de Derecho Transnacional (CDT), vol. $11, \mathrm{n}^{\circ} 2$, octubre 2019 , p. 787.

${ }^{139}$ STEDH Gran Sala 24 enero 2017, 25358/12, Paradiso Campanelli (ECLI:CE:ECHR:2017:0124JUD002535812), apartado 208. Vid. A.-M. Ruiz Martín, "El caso Campanelli y Paradiso ante el Tribunal Europeo de Derechos Humanos: El concepto de familia de facto y su aportación al debate de la gestación por sustitución", Cuadernos de Derecho Transnacional (CDT), vol. 11, nº 2, octubre 2019, p. 787.

${ }^{140}$ STEDH Gran Sala 24 enero 2017, 25358/12, Paradiso Campanelli (ECLI:CE:ECHR:2017:0124JUD002535812), apartados 140 y ss..

${ }^{141}$ L. Acconciamessa, "The Italian Constitutional Court Asked to Rule on Surrogacy Arrangements and Public Police",
} 
57. El Tribunal Supremo entendió que el orden público debía ser una combinación de fuentes de derechos humanos nacionales e internacionales, por lo que el principio del interés superior del niño tenía que formar parte del orden público internacional italiano.

Se debe realizar un balance, para llegar a un equilibrio, entre, por un lado, el interés del niño a que se reconozca su vínculo de filiación con el padre comitente (derechos individuales); y, por otro lado, los intereses del Estado en evitar el reconocimiento de actos que son percibidos por la sociedad como incompatibles con los valores fundamentales nacionales. Como resultado, se deberá proceder a la aplicación de una ley extranjera o al reconocimiento de sentencias extranjeras, incluso cuando se estén contraviniendo normas internas (ordinarias), siempre que los principios supremos del orden jurídico, en particular, los relativos a los derechos fundamentales y la dignidad humana, no sean infringidos.

Sin embargo, la "adopción en casos particulares" no implica un equilibrio justo de intereses, puesto que, en el ordenamiento italiano, este tipo de adopción no crea vínculos familiares completos entre padres e hijos, requiere un procedimiento complejo de nucho tiempo, exponiendo al niño a un período de incertidumbre. Tampoco es equiparable la "adopción en casos particulares" a la filiación natural, al no implicar vínculos familiares entre el niño y los parientes del adoptante, ni derechos sucesorios. Aunque el margen de dicrecionalidad que otorga el TEDH es amplio en cuanto a los medios por los cuales se puede reconocer el vínculo de filiación, no lo es tanto en lo que respecta a la "intensidad" $y$ al contenido de dichas relaciones ${ }^{142}$.

En este sentido, en Francia la adopción plena genera los mismos vínculos familiares que la filiación natural y los procedimientos de adopción plena tienen una duración de alrededor cuatro meses, tal y como ha señalado el TEDH en su reciente sentencia de 16 de julio de 2020, asunto D. c Francia ${ }^{143}$. Sin embargo, en Italia, donde no se permite la adopción plena en las mismas circunstancias, la inscripción del certificado de nacimiento extranjero parece ser la única alternativa válida, no sólo para el asunto que planteábamos al principio del epígrafe, sino para todos los casos similares, en los que el padre comitente no es el padre biológico ${ }^{144}$.

58. Por todos estos motivos, en abril del 2020, el Tribunal Supremo hizo una consulta al Tribunal Constitucional italiano relativa a si la interpretación que se ha venido haciendo, de no reconocimiento de la filiación a favor de los padres comitentes porque atenta contra el orden público, es coherente con la Constitución italiana.

En definitiva, la cuestión que se plantea es, si la regulación internacional existente en materia de Derechos Humanos, como el CEDH o el CDN, afecta a la capacidad de las autoridades estatales de rechazar el reconocimiento de las relaciones familiares y estatutos personales creadas en el extranjero válidamente, como consecuencia de la excepción de orden público. Ahora bien, en caso de conflicto las normas ordinarias deben declararse inconstitucionales, en virtud de art. 117 de la Constitución italiana.

Así pues, si el Tribunal Constitucional italiano concluye que la interpretación actual de la defensa del orden público es la correcta, los padres comitentes podrían recurrir al TEDH, por violación del art. 8 del CEDH. Si bien esto parece poco probable, porque el propio Tribunal Constitucional ya ha señalado anteriomente que los contratos de gestación por sustitución vulneran la dignidad de la mujer y que la "adopción en casos particulares" es una alternativa adecuada al reconocimiento (pleno) de la

EAPIL (The European Association of Private International Law), 28 septiembre 2020, disponible en https:/eapil.org/2020/09/28/ the-italian-constitutional-court-asked-to-rule-on-surrogacy-arrangements-and-public-policy/?utm_source=mailpoet\&utm medium=email\&utm_campaign=new-contents-on-the-eapil-blog_2 (consultado el 1 de abril de 2021).

${ }^{142}$ L. Acconciamessa, "The Italian Constitutional Court Asked to Rule on Surrogacy Arrangements and Public Police", EAPIL (The European Association of Private International Law), 28 septiembre 2020, disponible en https://eapil.org/2020/09/28/ the-italian-constitutional-court-asked-to-rule-on-surrogacy-arrangements-and-public-policy/?utm_source=mailpoet\&utm medium=email\&utm_campaign=new-contents-on-the-eapil-blog_2 (consultado el 1 de abril de 2021).

${ }^{143}$ STEDH 16 julio 2020, 11288/18, D c Francia, (JUR\2020\214195) (ECLI:CE:ECHR:2020:0716JUD001128818), apartados 66 y 67.

${ }^{144}$ L. Acconciamessa, "The Italian Constitutional Court Asked to Rule on Surrogacy Arrangements and Public Police", EAPIL (The European Association of Private International Law), 28 septiembre 2020, disponible en https://eapil.org/2020/09/28/ the-italian-constitutional-court-asked-to-rule-on-surrogacy-arrangements-and-public-policy/?utm_source=mailpoet\&utm medium=email\&utm_campaign=new-contents-on-the-eapil-blog_2 (consultado el 1 de abril de 2021). 
relación padre-hijo ${ }^{145}$. También se ha pronunciado en contra de la filiación a favor de las personas del mismo sexo, de niños nacidos mediante técnicas de reproducción asistida ${ }^{146}$.

Por lo tanto, será el Tribunal Constitucional el que decidirá si Italia se encuentra en una situación sistémica y persistente de incumplimiento del $\mathrm{CEDH}^{147}$.

59. En definitiva, se podría afirmar que existe un orden públio europeo, compuesto por derechos como el del art. 3 del CDN que recoge el interés superior del menor y por derechos como el "derecho a la vida privada y familiar", de conformidad con el art. 8 del CEDH. Si bien, por un lado, el Tribunal Supremo considera que el principio del interés superior del menor forma parte del orden público internacional italiano. Mientras que, por otro lado, las Joint Chambers, hacen prevelecer por encima del interés superior del menor otros principios, como son el de la dignidad de la mujer o incluso normas que prohíben a las personas del mismo sexo tener hijos mediante técnicas de reproducción asistida. De ahí, la consulta realizada por el Tribunal Supremo al Tribunal Constitucional, en relación a la constitucionalidad de determinados preceptos de su legislación ordinaria.

\section{Conclusiones}

60. El Tribunal Supremo español en su sentencia de 6 de febrero de 2014, ha señalado que la cláusula de orden público internacional español impide considerar válido y ejecutar en España un contrato de gestación por sustitución, así como el reconocimiento de la decisión registral extranjera en lo que respecta a la filiación que en ella se determine. Si bien una vez que el núcleo familiar ya existe y si los menores tienen relaciones familiares "de facto" con los padres comitentes, se tendría que tener en cuenta este dato, para permitir el desarrollo y la protección de estos vínculos -respeto a la vida privada y familiar (art. $8 \mathrm{CEDH}$ )-. Para ello, el ordenamiento español, permite la reclamación de la paternidad respecto del padre biológico, por si alguno de los padres comitentes lo fuera; y el que no fuera padre biológico, podría optar por figuras jurídicas como el acogimiento familiar o la adopción.

Sin embargo, en la Sentencia de la Audiencia Provincial de Islas Baleares del 27 de abril de 2021, el interés superior del menor prevalece sobre cualquier otra consideración, de forma que una vez, que se ha observado que el contrato de gestación por sustitución ha cumplido con las garantías requeridas para las partes y la menor en el Estado de celebración, la autoridad de cada Estado tiene un margen de discrecionalidad limitado para proponer un mecanismo eficaz que permita reconocer la relación entre el niño y la madre comitente a la mayor brevedad posible. Como las soluciones ofrecidas por el Tribunal Supremo en su sentencia de 6 de febrero de 2014, no pueden aplicarse al asunto que se está dirimiendo, la única posibilidad es proceder a la inscripción de la filiación de la menor a favor de la madre comitente.

Por lo que, tras esta sentencia, en materia de gestación por sustitución, se podría afirmar que existe un incipiente orden público europeo que prevalece sobre el orden público internacional, en este caso, del Estado español. Dicho orden público español estaría integrado no sólo por los principios recogidos en el Convenio Europeo de Derechos Humanos, como son el derecho al "respeto a la vida privada y familiar" (art. 8); sino por los principios contenidos en la Convención de los Derechos del Niño, concretamente el principio del "interés superior del menor" (art. 3) y el derecho a que el niño sea inscrito inmediatamente después de su nacimiento y el derecho a que tenga un nombre desde que nace y a adquirir una nacionalidad (art. 7.1).

${ }^{145}$ Sentencia núm. 272 de 2017, disponible en línea en https://www.giurcost.org/decisioni/2017/0272s-17.html (consultado el 1 de mayo de 2021).

${ }^{146}$ Sentencia núm. 221 de 2019, disponible en línea en https://www.cortecostituzionale.it/actionSchedaPronuncia. do? anno=2019\&numero=221 (consultado el 1 de mayo de 2021)

${ }^{147}$ L. Acconciamessa, "The Italian Constitutional Court Asked to Rule on Surrogacy Arrangements and Public Police", EAPIL (The European Association of Private International Law), 28 septiembre 2020, disponible en https:/eapil.org/2020/09/28/ the-italian-constitutional-court-asked-to-rule-on-surrogacy-arrangements-and-public-policy/?utm_source=mailpoet\&utm _ medium=email\&utm_campaign=new-contents-on-the-eapil-blog_2 (consultado el 1 de abril de 2021). 
Si bien dado que se trata de principios que recogen derechos fundamentales del CEDH y que forman parte del orden público de cada Estado, la expresión más apropiada sería que el orden público internacional de cada Estado estaría integrado por el orden público europeo, además de por el conjunto de principios fundamentales que garantizan la cohesión jurídica de la sociedad de cada país.

61. Por otro lado, de las sentencias de de 26 de junio de 2014 en los asuntos Mennesson y Labassee podría concluirse que el TEDH apuesta por una concepción restrictiva y específica del orden público internacional, de manera que viene a limitar la aplicación del orden público y sólo debe activarse en supuestos concretos en los que exista una situación grave real tanto para la madre gestante como para el menor. En definitiva, se está limitando el concepto de orden público de cada Estado, cuando se trata del reconocimiento del vínculo de filiación entre los padres comitentes y el menor que ha nacido mediante un contrato de gestación por sustitución en el extranjero.

Sin embargo, tras el primer Dictamen del TEDH puede afirmarse que, aunque existe un limitado margen de discrecionalidad de los Estados miembros en el reconocimiento del vínculo de filiación, existe un amplio margen de apreciación de los Estados en la elección de los medios jurídicos para llevar a cabo el mismo, que bien puede tratarse de la adopción, siempre que se procure prontitud en el procedimiento. No se exige, por tanto, la inmediata inscripción de los datos que figuran en la certificación registral extranjera, en el Registro Civil nacional correspondiente.

En este sentido, el margen en la exclusividad estatal de delimitación del orden público estatal va desapareciendo progresivamente conforme el TEDH va resolviendo más y más casos específicos, en relación con diferentes materias. Puesto que, cuando el TEDH resuelve si un Estado ha vulnerado o no alguno de los derechos consagrados por el CEDH -que a su vez forma parte integrante de su orden público- la concreción del contenido del derecho humano en cuestión, para este supuesto de gestación por sustitución, también determina el contenido del orden público de todos los Estados parte del CEDH.

En definitiva, como se ha señalado en el epígrafe segundo, existiría un orden público europeo integrado no sólo por los principios recogidos en el Convenio Europeo de Derechos Humanos, como son el derecho al "respeto a la vida privada" (art. 8), sino por los principios contenidos en la Convención de los Derechos del Niño, concretamente el principio del "interés superior del menor" (art. 3).

62. Sin embargo, las diferencias entre las soluciones adoptadas por el TEDH en los asuntos Mennesson y Labassee y el Tribunal Supremo en el caso de los "niños de California", no han resultado ser reales en la práctica, tal y como se ha puesto de manifiesto a raíz de la consulta realizada por la Cour de Cassation francesa al TEDH precisamente en relación con el asunto Mennesson.

En su primer Dictamen en relación con la gestación por sustitución, el TEDH señala que el reconocimiento de la filiación de las hijas Mennesson en relación con la madre comitente, no tiene que hacerse por la transcripción del acta de nacimiento legalmente establecido en el extranjero, sino por cualquier otra vía como la adopción, siempre que las modalidades previstas en el derecho interno garanticen la efectividad y la celeridad del reconocimiento de la filiación, de conformidad con el interés superior del menor.

Si bien, la solución es similar a la ofrecida por el Tribunal Supremo para el reconocimiento de la filiación a favor del padre que no resulte ser el padre biológico, es decir, que dichos padres comitentes no biológicos tienen la posibilidad el acogimiento o la adopción. Sin embargo, ninguna de estas dos opciones es rápida en el ordenamiento español. En Francia por otro lado, aunque en el asunto $D$ c. Francia, el TEDH señaló que la adopción plena tiene una duración de alrededor cuatro meses; en relación con el asunto Mennesson el juez consideró que, después de quince años de procedimiento judicial, el interés superior del menor requería un reconocimiento inmediato de la relación materno-filial, sin tener que recurir a los trámites de la adopción.

Así pues, la diferencia entre el caso español y el francés es que en el caso francés, uno de los padres comitentes demostró a lo largo del procedimiento que era el padre biológico de los menores, mientras que en el caso español, esto no quedó probado, aunque sí que fue puesto de manifiesto a lo largo de las diferentes instancias que atravesó el asunto. Aunque el hecho de que ninguno de los padres 
comitentes sea el padre biológico del menor, no parece ser relevante para que exista un núcleo familiar de "facto" y se respete el derecho a la "vida privada y familiar", de acuerdo con el art. 8 del TEDH; la realidad es que, la ausencia de carga genética en el menor fue uno de los motivos, entre otros, para que finalmente, el TEDH no considerara que había habido una injerencia en el derecho a la vida privada y familiar por el Estado italiano en el asunto Paradiso Campanelli.

En cualquier caso, el TEDH y el Tribunal Supremo sí que coinciden en que debe respetarse el núcleo familiar "de facto" constituido en el país de destino, siendo un medio idóneo para la protección del mismo, la concesión del derecho a la prestación de maternidad a los padres comitentes. Precisamente, porque existía un núcleo familiar de "facto" en el Estado de origen, en la Sentencia de la Audiencia Provincial de Islas Baleares de 27 de abril de 2021, se permitió la inscripción de la certificación registral de nacimiento de una niña nacida en Rusia mediante gestación por sustitución, en aras del principio del interés superior del menor. Para ello, se tuvieron en cuenta todas las circunstancias del caso: no era posible recurrir a ninguna de las soluciones previstas por el Tribunal Supremo, dado que no se podía identificar al padre biológico, pues se trataba de un donante anónimo; y no se cumplían las condiciones legales para la adopción o el acogimiento bajo la legislación española.

63. En Italia, existe una situación similar a la de España y Francia, en el sentido de que, tal y como señaló el Ministerio Fiscal en contra de la Sentencia del Tribunal de Apelación de Venecia, las normas italianas sobre filiación y técnicas de reproducción asistida, no permiten el reconocimiento de la filiación a favor del padre comitente que no es el padre biológico de un niño nacido mediante gestación por sustitución en Canada. Sin embargo, sí que es posible el reconocimiento de la filiación a favor del otro padre comitente, porque además es el padre biológico. Al padre comitente no biológico, se le ofrece la posibilidad de adoptar.

En este sentido, Italia está teniendo en cuenta el interés superior del menor (art. $3 \mathrm{CDN}$ ) y el restrictivo margen de discrecionalidad con el que en la actualidad cuentan los Estados parte del CEDH, para no permitir el reconocimiento del vínculo de filiación de los menores nacidos en el extranjero mediante los contratos des gestación por sustitución. Todo ello, a pesar del precedente que generó la actuación del gobierno italiano en el asunto Paradiso y Campanelli, en el que el margen de apreciación fue bastante amplio. Aunque se debe decir en defensa del gobierno italiano, que este asunto es anterior a la reciente jurisprudencia del TEDH, en la que se ha establecido de forma clara el restrinido margen de apreciación por los Estados para rechazar los contratos de gestación de sustitución, en condiciones similares a las que se plantean en dichos supuestos.

Por otro lado, el margen de dicrecionalidad que otorga el TEDH es amplio en cuanto a los medios por los cuales se puede reconocer el vínculo de filiación, no lo es tanto en lo que respecta a la "intensidad" y al contenido de dichas relaciones. Por esta razón, en el caso de Italia, genera cuanto menos dudas, la "adopción en casos particulares", puesto que la misma no es equiparable a la filiación natural y supone un procedimiento rápido y complejo. Así que, la inscripción del certificado de nacimiento extranjero parece ser la única alternativa válida en el caso de Italia, para cumplir con lo establecido por el TEDH.

De ahí, que el Tribunal Supremo se haya visto en la necesidad de plantear la cuestión inconstitucionalidad de las normas que contravengan los principios fundamentales del CEDH.

En este sentido, aunque en España y Francia no se ha realizado una consulta de similares características, las últimas sentencias tanto la Sentencia de la Audiencia Provincial de Islas Baleares de 27 de abril de 2021, como la Sentencia de 16 de julio de 2020, asunto D. c. Francia, están respetando las directrices que viene encomendando el TEDH a través de su jurisprudencia.

64. En definitiva, se puede afirmar que existe un orden público europeo, que en materia de gestación por sustitución, estaría formado por los principios recogidos en el Convenio Europeo de Derechos Humanos, como son el derecho al "respeto a la vida privada y familiar" (art. 8); y por los principios contenidos en la Convención de los Derechos del Niño, concretamente el principio del "interés superior del menor" (art. 3) y el derecho a que el niño sea inscrito inmediatamente después de su nacimiento y el derecho a que tenga un nombre desde que nace y a adquirir una nacionalidad (art. 7.1). 
Si bien, tras este análisis, dado que el orden públio europeo estaría conformado por principios que recogen derechos fundamentales del CEDH y del CDN, se podría concluir que dicho orden público europeo formaría parte del orden público internacional de cada Estado, además de estar comprendido este último, por el conjunto de principios fundamentales que garantizan la cohesión jurídica de la sociedad de cada país. 